\title{
Thermochemical and Structural Studies of Gallic and Ellagic
}

\section{Acids}

Juan Z. Dávalos ${ }^{1 *}$, Carlos F. R. A. C. Lima ${ }^{2,3}$, Luís M. N. B. F. Santos ${ }^{2}$, Violeta L. Romero ${ }^{4}$ and Joel F. Liebman ${ }^{5}$

${ }^{1}$ Instituto de Química-Física “Rocasolano”, CSIC, Serrano 119, 28006, Madrid, Spain.

${ }^{2}$ Centro de Investigação em Química, Departamento de Química e Bioquímica, Faculdade de Ciências da Universidade do Porto, Rua do Campo Alegre, 687, P-4169-007 Porto, Portugal

${ }^{3}$ Department of Chemistry \& QOPNA, University of Aveiro, Aveiro 3810-193, Portugal

${ }^{4}$ Facultad de Ingeniería Industrial y de Sistemas, Universidad Nacional Federico Villarreal, Av. Colonial 450, Lima 01, Perú

${ }^{5}$ Department of Chemistry and Biochemistry, University of Maryland, Baltimore County, Baltimore, MD 21250, USA

* Corresponding author:

Tel.: +34919619400

E-mail address: jdavalos@iqfr.csic.es

This paper is dedicated to Prof. Gennady Kabo on the occasion of his $80^{\text {th }}$ birthday. 


\section{Abstract}

We report a study on the energetics and structural properties of gallic (1) and ellagic (2) acids. The experimental values of standard enthalpy of formation in solid state at $298.15 \mathrm{~K}$, $\Delta_{\mathrm{f}} H_{\mathrm{m}}^{0}(\mathrm{~cd})$ of 1 as $\left(-985.0 \pm 2.9 \mathrm{~kJ} \cdot \mathrm{mol}^{-1}\right)$ and 2 as $\left(-1377.9 \pm 4.7 \mathrm{~kJ} \cdot \mathrm{mol}^{-1}\right)$ have been determined. The vapor pressure of $\mathbf{1}$ have been measure by Knudsen effusion methodology and the derived enthalpy of sublimation, $\Delta_{\mathrm{cd}}^{g} H_{m}^{0}$, was combined with the $\Delta_{\mathrm{f}} H_{\mathrm{m}}^{0}$ (cd) in order to derive its gas-phase enthalpy of formation, $\Delta_{\mathrm{f}} H_{\mathrm{m}}^{0}(\mathbf{1}, \mathrm{g})=-835.7 \pm 4.0 \mathrm{~kJ} \cdot \mathrm{mol}^{-1}$. Quantum chemical calculations, at DFT (M05-2X) and composite ab initio Gn $(\mathrm{n}=3,4)$ levels of theory, provided the consistency of the experimental results and a plausible estimation of $\Delta_{\mathrm{f}} H_{\mathrm{m}}^{0}(\mathrm{~g})$ of 2 as $\left(-1128.6 \pm 6.4 \mathrm{~kJ} \cdot \mathrm{mol}^{-1}\right)$, which was deduced from the isodesmic-reactions methodology.

Keywords: gallic-ellagic acids; Knudsen effusion; combustion calorimetry; enthalpy of formation; $\mathrm{Gn}(\mathrm{n}=3,4)$; DFT(M05-2X) 


\section{Introduction}

Gallic (1) and ellagic (2) acids are polyphenols present in numerous fruits and vegetables, including nuts, grapes, berries and also beverages such as tea and wine. Both compounds, and their derivatives (e.g. the hydrolysable tannins), are objects of numerous investigations, since they are considered as potent and versatile antioxidants with promising therapeutic and industrial applications [1]-[6].

Ellagic acid (2) is a dimeric form of gallic acid (1) (See Scheme 1), and comprised of a fused four-ring structure with four hydroxyl groups and two lactone rings representing the hydrophilic part. The antioxidant activity of these compounds are related to their molecular structure, particularly to the presence and the number of hydroxyl groups, to the conjugation and the resonance effects and also to the capacity to improve the stability of their corresponding phenoxyl radicals [7]-[10].

Despite the fundamental and applied relevance of $\mathbf{1}$ and $\mathbf{2}$, the thermochemical data of both acids are incomplete. Herein we report a reliable experimental data of standard enthalpy of formation in the solid state at $298.15 \mathrm{~K}, \Delta_{\mathrm{f}} H_{\mathrm{m}}^{0}(\mathrm{~cd})$, of $\mathbf{1}$ and 2 by using static micro-bomb combustion calorimetry measurements. The standard enthalpy of sublimation, $\Delta_{\mathrm{cd}}^{g} H_{m}^{0}$, of $\mathbf{1}$, was also determined experimentally by Knudsen-effusion technique. This value allowed us to determine the standard enthalpy of formation in the gas phase, $\Delta_{\mathrm{f}} H_{\mathrm{m}}^{0}(\mathrm{~g})$, of 1. Unfortunately, our attempts to determine $\Delta_{\mathrm{cd}}^{g} H_{m}^{0}$ of $\mathbf{2}$, by Knudseneffusion or Calvet-microcalorimetry techniques, were unsuccessful due to the very low volatility of this compound. 
Quantum chemical calculations at the density functional theory (M05-2X) level and composite ab initio G3 and G4 methods allowed us to discuss and check the consistency of the obtained results. These calculation methodologies were also used to determine $\Delta_{\mathrm{f}} H_{\mathrm{m}}^{0}(\mathrm{~g})$ of 2 by means of isodesmic reactions, which combine theoretical and available experimental data of the involved compounds.

\section{SCHEME 1 here}

\section{Experimental Section}

\subsection{Materials and DSC measurements.}

3,4,5-Trihydroxybenzoic acid $\left(\mathrm{C}_{7} \mathrm{H}_{6} \mathrm{O}_{5}, \mathbf{1}\right.$, gallic acid, CAS 149-91-7) and 2,3,7,8Tetrahydroxychromeno[5,4,3-cde]chromene-5,10-dione $\left(\mathrm{C}_{14} \mathrm{H}_{6} \mathrm{O}_{8}, \mathbf{2}\right.$, ellagic acid, CAS 476-66-4) were purchased from Sigma-Aldrich, carefully dried under vacuum at $363.15 \mathrm{~K}$ and used without further purification. Table 1 summarizes relevant information on purity and provenance of samples. The thermophysical properties were derived from DCS (Perkin Elmer Pyris 1) results over the temperature ranges considered (see below). Molar heat

capacities at constant pressure $C_{p, \mathrm{~m}}^{0}$ were also experimentally determined by DSC. Full details are given in the Supplementary Information (S1).

\section{$\underline{\text { TABLE } 1 \text { here }}$}




\subsection{Combustion calorimetry.}

The combustion experiments were performed in an isoperibol static micro-bomb calorimeter. Detailed description of this method is found elsewhere [11]. The energy equivalent of the calorimeter $\varepsilon$ (calor) was determined from the combustion of benzoic acid (NIST standard reference sample 39j) which massic energy of combustion is $-26434 \pm 3$ $\mathrm{J} \cdot \mathrm{g}^{-1}$, under certificated conditions. From 10 calibration experiments, carried out in oxygen atmosphere at $p=3.04 \mathrm{MPa}$ with $0.05 \mathrm{~cm}^{3}$ of water added to bomb calorimeter, we obtained $\varepsilon$ (calor) of $2105.3 \pm 0.3 \mathrm{~J} \cdot \mathrm{K}^{-1}$, where the uncertainty quoted is the standard deviation of the mean. As fuse was used cotton-thread, of which the empirical formula $\left(\mathrm{CH}_{1.740} \mathrm{O}_{0.871}\right)$ and massic energy of combustion $\left(-17410 \pm 37 \mathrm{~J} \cdot \mathrm{g}^{-1}\right)$ were determined in our laboratory [12].

Solid samples of both $\mathbf{1}$ and $\mathbf{2}$ compounds were pressed in pellet forms, weighted in a Mettler UMX2 microbalance $( \pm 0.1 \mu \mathrm{g})$ and burned in similar conditions to those used in the calibration experiments with benzoic acid. In order to obtain complete combustion reactions, vaseline, with massic energy of combustion of $-46086 \pm 5 \mathrm{~J} \cdot \mathrm{g}^{-1}$, [13] was used as auxiliary substance. After disassembly of the calorimeter, gases were slowly released and the absence of CO was checked with Dragër tubes (with sensitivity levels approximately of $1 \times 10^{-6}$ mass fraction). Corrections of apparent mass to mass, conversion of the energy of the actual bomb process to that of the isothermal process, nitric acid formation and correction to standard states were made according to Hubbard et al. [14]. For these corrections were used density $\rho$ values, taken from Reaxys-Database, of 1.694 (at RT) and 1.667 (at $291.15 \mathrm{~K}$ ) $\mathrm{g} \cdot \mathrm{cm}^{-3}$ for $\mathbf{1}$ and $\mathbf{2}$ respectively; the massic heat capacities $c_{p}$ were taken 
from this work (Table S1) and $(\partial V / \partial T)_{p}$, for both compounds, were assumed as $3.85 \times 10^{-7}$ $\mathrm{dm}^{3} \cdot \mathrm{g}^{-1} \cdot \mathrm{K}^{-1}[15]$. The molar masses used for the elements were those recommended by the IUPAC commission [16]. Complementary details are given in the Supplementary Information (S2).

\subsection{Enthalpy of sublimation measurements. Knudsen/Quartz effusion technique.}

The standard molar enthalpy of sublimation, $\Delta_{\mathrm{cd}}^{g} H_{m}^{o}$, and other thermodynamic related functions for gallic acid (1) were derived from vapor pressures measurements, which were determined, as a function of temperature, through gravimetric analysis of Knudsen cell before and after each effusion experiment, carried out in a combined Knudsen/Quartz crystal effusion apparatus [17]. The equilibrium vapor pressures of $\mathbf{1}$ were measured in the following ranges: 432.8 to $458.8 \mathrm{~K}$ and 0.0961 to $0.9376 \mathrm{~Pa}$ (See Supplementary Information, S3). Attempts were made to measure the vapor pressures of compound 2, but unfortunately that was not possible. No measurable vapor pressure was detected until the temperature of the Knudsen apparatus (around $573 \mathrm{~K}$ ). Moreover, while heating the compound up to $593 \mathrm{~K}$ under vacuum in a micro-sublimation apparatus used for compound purification, no solid sublimed and the compound appeared to start decomposing.

\subsection{Computational methods}

The quantum chemical calculations were carried out using the Gaussian 09 package. The geometries of the compounds studied and those of the reference systems used in the isodesmic reactions considered were optimized by using density functional theory (DFT), 
with the M05-2X Truhlar functional [18] and the 6-311++G(d,p) basis set without symmetry restrictions. Harmonic vibrational frequencies were also calculated at the same level without scaling. The computed energies and enthalpies for the most stable molecules studied are described in detail in Supplementary Information (S4).

Furthermore, to confirm the reliability of the measured enthalpy of formation of $\mathbf{1}$ we have obtained theoretical values using the high-level $a b$ initio approaches G3 [19] and G4 [20] theories. In both methods, theoretical enthalpies of formation in the gas phase can be estimated through atomization reactions [21]. It is important to mention that the G3 theoretical procedure modifies and corrects many of the deficiencies of the $\mathrm{Gn}(\mathrm{n}=1,2)$ theory and in turn, G4 improves G3 mainly in the geometry optimizations and zero-point energy corrections. The level of theory employed in the present work is expected to provide reasonable values of reaction energetics [22].

In general, the theoretical optimized geometries for the structures of these compounds are in good agreement with the available experimental XRD and neutrondiffraction data. The observed deviations can be attributed to the fact that the experimental structure is determined in solid state, while the calculations refer to the gas phase.

\section{Results and discussion}

\subsection{Thermophysical Properties.}

The onset temperature of melting point for 1 was estimated by DSC technique as $T_{\text {fus }}$ $=536.6 \pm 0.6 \mathrm{~K}$, where the associated uncertainty is expressed as expanded uncertainty of the mean $(0.95$ level of confidence, coverage factor $k=2)$ for three experiments. This value 
is in good agreement with that reported by Queimada et al. [23]. It is important to mention that we have not observed a solid-solid phase transition at $351.31 \mathrm{~K}$ reported by BogelŁukasik et. al [24]. It could be because we have used samples previously dried under vacuum at $363.15 \mathrm{~K}$.

The melting peak of $\mathbf{1}$ is not symmetric, suggesting that decomposition may occur upon melting, as supported by the TGA results reported in the literature [25]-[27]. Therefore, parameters such as enthalpy of fusion could not be determined by DSC measurements [23].

The DSC thermogram of $\mathbf{2}$ doesn't show significant changes in the measurement range from 263 to $750 \mathrm{~K}$. The DSC thermogram obtained by Zhao et al. [28] shows a short peak around $765 \mathrm{~K}$, attributed by them as melting process. This peak disappeared for micronized 2 freeze-dried powder. Their TGA results indicate a strong decomposition (82 $\%$ weight loss) of pure 2 at 905 K. Similar TGA decomposition patterns were also report by Mirulanini et al. [29] and Hussein et al. [30]

The least-square fitting of the experimental data of molar heat capacities in the solid state $C_{p, m}^{0}\left(\right.$ in $\left.\mathrm{J} \cdot \mathrm{K}^{-1} \cdot \mathrm{mol}^{-1}\right)$ yielded the following equations:

For $\mathbf{1}$, in the range of (263.15 to 471.15$) \mathrm{K}$,

$$
C_{p, m}^{0}(\mathrm{~cd}, T)=4.53 \cdot 10^{-4}(T / \mathrm{K})^{2}+2.3484 \cdot 10^{-1}(T / \mathrm{K})+87.916 \quad\left(\mathrm{r}^{2}=0.96\right)
$$

For 2 , in the range of (260.15 to 522.15$) \mathrm{K}$,

$$
C_{p, m}^{0}(\mathrm{~cd}, T)=-1.1 \cdot 10^{-3}(T / \mathrm{K})^{2}+1.6866(T / \mathrm{K})-74.016 \quad\left(\mathrm{r}^{2}=0.999\right)
$$

Details are given in Supplementary Information (S1). 


\subsection{Combustion calorimetry and Knudsen Effusion technique.}

Standard enthalpies of formation of the gallic and ellagic acids.

Processes involved in the combustion of $\mathbf{1}$ and $\mathbf{2}$ are represented by reactions (3) and (4). Results for typical combustion experiments, including the mean value of massic energy of combustion $\left\langle\Delta_{c} u^{0}(298.15 \mathrm{~K})>\right.$, are given in Table 2 . The detailed results for all combustion experiments are shown in Supplementary Information (Table S2).

$$
\begin{aligned}
& \mathrm{C}_{7} \mathrm{H}_{6} \mathrm{O}_{5}(\mathbf{1}, \mathrm{cd})+6 \mathrm{O}_{2}(\mathrm{~g}) \longrightarrow 7 \mathrm{CO}_{2}(\mathrm{~g})+3 \mathrm{H}_{2} \mathrm{O}(\mathrm{l}) \\
& \mathrm{C}_{14} \mathrm{H}_{6} \mathrm{O}_{8}(\mathbf{1}, \mathrm{cd})+11.5 \mathrm{O}_{2}(\mathrm{~g}) \longrightarrow 14 \mathrm{CO}_{2}(\mathrm{~g})+3 \mathrm{H}_{2} \mathrm{O}(\mathrm{l})
\end{aligned}
$$

The standard $\left(p^{0}=0.1 \mathrm{MPa}\right)$ molar enthalpies of combustion, $\Delta_{\mathrm{c}} H_{\mathrm{m}}^{0}(\mathrm{~cd})$, and formation, $\Delta_{\mathrm{f}} H_{\mathrm{m}}^{0}(\mathrm{~cd})$, in the solid phase at temperature $T=298.15 \mathrm{~K}$ are shown in Table 3 . The values for the standard molar enthalpies of formation of $\mathrm{H}_{2} \mathrm{O}(\ell)$ and $\mathrm{CO}_{2}(\mathrm{~g})$ at $T=298.15$ $\mathrm{K}$ are $-(285.830 \pm 0.042)$ and $-(393.51 \pm 0.13) \mathrm{kJ} \cdot \mathrm{mol}^{-1}$, respectively, were taken from CODATA [31].

\section{TABLE 2 here}

The enthalpy of sublimation 1 was deduced from the temperature dependence of the vapour pressure, using the Clausius-Clapeyron equation: $\ln p=-\mathrm{B} \cdot(T)^{-1}+\mathrm{A}$. This equation was fitted by the least squares method (Figure 1) to obtain the molar enthalpy of 
sublimation at the mean temperature, $T_{\mathrm{m}}$, from $\mathrm{B}=\Delta_{\mathrm{cd}}^{\mathrm{g}} H_{\mathrm{m}}^{0}\left(T_{\mathrm{m}}\right) / \mathrm{R}$. The standard molar enthalpy of sublimation, $\Delta_{\mathrm{cd}}^{\mathrm{g}} H_{\mathrm{m}}^{0}$, at $T=298.15 \mathrm{~K}$ was computed using the equation (5):

$$
\Delta_{\mathrm{cd}}^{\mathrm{g}} H_{\mathrm{m}}^{0}(T=298.15 K)=\Delta_{\mathrm{cd}}^{\mathrm{g}} H_{\mathrm{m}}^{0}\left(T_{\mathrm{m}}\right)+\int_{T m}^{298.15}\left[C_{p, m}^{0}(g)-C_{p, m}^{0}(\mathrm{~cd})\right] d T
$$

where the $C_{p, m}^{0}(\mathrm{~g})=f(T)$ values were derived from computational data at G3 theory and the $C_{p, m}^{0}(\mathrm{~cd})=f(T)$ values were obtained from the experimental DSC measurements (eq. 1). Dimerization in the gas phase shall not be significant at the very low vapor pressures (below $1 \mathrm{~Pa}$ ) and relatively high temperatures (around $446 \mathrm{~K}$ ) used in the Knudsen experiments. The correlation coefficient of the linear regression shown in figure 1, obtained by the Knudsen effusion method, is somewhat lower than usual. Despite of this, the errors on the measured vapor pressures are small and the residual analysis confirm the absence of significant systematic errors in the results.

\section{FIGURE 1 here}

The standard molar enthalpies of combustion $\Delta_{\mathrm{c}} H_{\mathrm{m}}^{0}(\mathrm{~cd})$ and formation $\Delta_{\mathrm{f}} H_{\mathrm{m}}^{0}(\mathrm{~cd})$, in the solid state at $T=298.15 \mathrm{~K}$, of $\mathbf{1}$ and $\mathbf{2}$ are given in Table 3. This table also includes the standard molar enthalpies of sublimation, $\Delta_{\mathrm{cd}}^{g} H_{m}^{0}$, and formation in gaseous state, $\Delta_{\mathrm{f}} H_{\mathrm{m}}^{0}(\mathrm{~g})$, of $\mathbf{1}$. The $\Delta_{\mathrm{c}} H_{\mathrm{m}}^{0}(\mathbf{1}, \mathrm{cd})$ and $\Delta_{\mathrm{f}} H_{\mathrm{m}}^{0}(\mathbf{1}, \mathrm{cd})$ values reported here are $27.5 \mathrm{~kJ} \cdot \mathrm{mol}^{-1}$ lower than old values reported by Lobanov and Karmanova [32], which were estimated without include corrections such as so-called Washburn-correction energies. 


\section{TABLE 3 here}

\subsection{Molecular structures and thermochemical properties of gallic and ellagic acids.}

The optimized geometry computed at different levels of theory showed that the most stable gallic (1 $\left.\mathbf{1}_{\mathrm{a}}\right)$ and ellagic acid ( $\left.\mathbf{2}_{\mathrm{a}}\right)$ molecules (Figure 2), among the conformers (rotamers) considered, exhibits a planar structure with $\mathrm{C}_{s}$ and $\mathrm{C}_{2 h}$ symmetries, respectively. The rotamers considered differ only in the orientations of the hydroxyl groups, which are described by $\theta\left(\theta^{\prime}\right), \omega\left(\omega^{\prime}\right)$ and $\phi\left(\phi^{\prime}\right)$ dihedral angles. $\mathbf{1}_{\mathrm{a}}$ and $\mathbf{2}_{\mathrm{a}}$ are characterized by the presence of catechol-aromatic groups with two intra-molecular hydrogen bonds between their phenolic $-\mathrm{OH}$ groups.

Rotation of the carboxylic moiety of $\mathbf{1}_{\mathrm{a}}\left(\alpha=0^{\circ}\right)$ around the $\mathrm{C}_{1(\mathrm{Ph})}-\mathrm{C}(\mathrm{OOH})$ bond leads to structure $\mathbf{1}_{\mathrm{b}}\left(\alpha=180^{\circ}\right.$, Fig. S2) which is almost $2 \mathrm{~kJ} \cdot \mathrm{mol}^{-1}$ less stable than $\mathbf{1}_{\mathrm{a}}$. The rotamers maintaining only one intramolecular H-bond (1 $\mathbf{1}_{\mathrm{c}}$ and $\mathbf{1}_{\mathrm{d}}$, Fig. S2) display enthalpy differences, relative to $\mathbf{1}_{\mathrm{a}}$, higher than $14 \mathrm{~kJ} \cdot \mathrm{mol}^{-1}$ and their contribution to the total population of $\mathbf{1}$ is less than $0.5 \%$ (Table S4). These results are close to those obtained by Badhani and Kakkar [33] at the B3LYP/6-311++G(2d,2p) level of theory.

The conformational analysis of $\mathbf{2}$ was performed by Marković et al. [34] at the same level used in our DFT calculations: $\mathbf{2}_{\mathrm{a}}$ is significantly more stable than the other rotamers $\left(\mathbf{2}_{\mathrm{x}}, \mathrm{x}=\mathrm{b}, \ldots, \mathrm{g}\right.$, Fig. S3), which display enthalpy differences, relative to $\mathbf{2}_{\mathrm{a}}$, higher than 14 $\mathrm{kJ} \cdot \mathrm{mol}^{-1}$ (Table S4). Therefore, the contribution of these $\mathbf{2}_{\mathrm{x}}$ rotamers to the total population of $\mathbf{2}$ is less than $1 \%$. 


\section{FIGURE 2 here}

The consistency of the experimental $\Delta_{\mathrm{f}} H_{\mathrm{m}}^{\mathrm{o}}(\mathbf{1}, \mathrm{g})$ value reported here, was checked by using, i/ the atomization method at G3 and G4 levels of theory. The values obtained were -839.5 and $-831.6 \mathrm{~kJ} \cdot \mathrm{mol}^{-1}$, respectively; which are close to the experimental one (differences are less than $4.1 \mathrm{~kJ} \cdot \mathrm{mol}^{-1}$ ); ii/ isodesmic reactions (6), (7) and (8), where the corresponding reaction enthalpies $\left(634.4,27.2\right.$ and $-0.5 \mathrm{~kJ} \cdot \mathrm{mol}^{-1}$, respectively) were obtained at the M05-2X/6-311++G(d,p) level of theory. These values, combined with the experimental $\Delta_{\mathrm{f}} H_{\mathrm{m}}^{0}(\mathrm{~g})$ of reference compounds, can be used to deduce an estimated $\Delta_{\mathrm{f}} H_{\mathrm{m}}^{0}(\mathrm{~g})$ of $\mathbf{1}$, which are in good agreement with the experimental value (deviations less than $3.7 \mathrm{~kJ} \cdot \mathrm{mol}^{-1}$ ) particularly if using the "bond separation isodesmic" reaction (6). For reference compounds, we have used the following experimental $\Delta_{\mathrm{f}} H_{\mathrm{m}}^{0}(\mathrm{~g})$ values, in $\mathrm{kJ} \cdot \mathrm{mol}^{-}$ ${ }^{1}$ : methane $(-74.87 \pm 0.34)$, ethane $(-84.0 \pm 0.4)$, ethene $(52.47 \pm 0.30)$, benzene $(82.9 \pm$ $0.9)$, formaldehyde $(115.9 \pm 6.3)$, phenol $(-96.36 \pm 0.59)$, acetic acid $(-433.0 \pm 2.5)$ and $1,2-$ benzenediol or catechol $(-274.8 \pm 1.2)$ from NIST [35]; methanol $(-201.5 \pm 0.2)$ from Pedley [36] and 3,4-dihydroxybenzoic acid from Monte et al. [37]

$$
\begin{aligned}
& \mathbf{1}+12 \cdot \text { methane } \longrightarrow \text { 4. ethane }+3 \cdot \text { ethene }+4 \cdot \text { methanol }+ \text { formaldehyde } \\
& \mathbf{1}+\text { benzene }+ \text { methane } \longrightarrow \text { phenol }+1,2 \text {-benzenediol }+ \text { acetic acid } \\
& \mathbf{1}+\text { benzene } \longrightarrow \text { 3,4-dihydroxybenzoic acid }+ \text { phenol }
\end{aligned}
$$

The enthalpy of reaction (8) gives us information about the effect of introduction of an $\mathrm{OH}$ group in the aromatic ring of 3,4-dihydroxybenzoic acid, measured relative to the 
same effect on benzene. The purely experimental value, $\Delta_{\mathrm{r}} H_{\mathrm{m}}^{0}(8)=3.2 \pm 5.2 \mathrm{~kJ} \cdot \mathrm{mol}^{-1}$, indicates that the effect of $\mathrm{OH}$ introduction in 3,4-dihydroxybenzoic acid (to yield $\mathbf{1}$ ) is practically the same as in benzene (to yield phenol). The trend of enthalpic stability increments $\left(\Delta \Delta_{\mathrm{f}} H_{\mathrm{m}}^{0}\right)$ due to the successive introduction of $\mathrm{OH}$ groups in benzoic acid $\left(\Delta_{\mathrm{f}} H_{\mathrm{m}}^{0}(\mathrm{~g})=-294.0 \pm 2.2 \mathrm{~kJ} \cdot \mathrm{mol}^{-1}[36]\right)$ to yield $\mathbf{1}$ is comparable to the corresponding $\Delta \Delta_{\mathrm{f}} H_{\mathrm{m}}^{0}$ in benzene to yield catechol but no pyrogallol (Scheme 2), since the last step of this sequence involves an abrupt change of almost $20 \mathrm{~kJ} \cdot \mathrm{mol}^{-1}$. We have found no reasonable explanation to justify this result, rather we believe that $\Delta_{\mathrm{f}} H_{\mathrm{m}}^{0}(\mathrm{~g})$ of pyrogallol (equal to $-434.2 \pm 1.1 \mathrm{~kJ} \cdot \mathrm{mol}^{-1}[38]$ ) should be re-evaluated (see Supplementary Information S5). It is important to mention that pyrogallol readily autooxidizes in air and this can complicate many measurements of its properties.

\section{SCHEME 2 here}

Similarly, we have considered the isodesmic reactions (9), (10) and (11) to estimate the standard enthalpy of formation of $2, \Delta_{\mathrm{f}} H_{\mathrm{m}}^{0}(\mathbf{2}, \mathrm{g})$ :

$$
\begin{aligned}
& \mathbf{2}+26 \cdot \text { methane } \longrightarrow 9 \cdot \text { ethane }+6 \cdot \text { ethene }+4 \cdot \text { methanol }+2 \cdot \text { formaldehyde }+2 \cdot \text { dimethyl } \\
& \text { ether } \\
& \mathbf{2}+2 \cdot \text { methane }+4 \cdot \text { methanol } \longrightarrow \text { ethane }+2 \cdot 1+\text { dimethyl ether } \\
& \mathbf{2}+6 \cdot \text { methane } \longrightarrow \text { ethane }+2 \cdot \text { catechol }+2 \cdot \text { methyl acetate }
\end{aligned}
$$


From the experimental $\Delta_{\mathrm{f}} H_{\mathrm{m}}^{0}(\mathrm{~g})$ value of $\mathbf{1}$ reported here and of the reference compounds such as dimethyl ether $\left(-184.1 \pm 0.5 \mathrm{~kJ} \cdot \mathrm{mol}^{-1}\right)[35]$, methyl acetate $\left(-413.3 \pm 0.4 \mathrm{~kJ} \cdot \mathrm{mol}^{-1}\right)$ [36] and others described above, we have deduced three $\Delta_{\mathrm{f}} H_{\mathrm{m}}^{0}(\mathrm{~g})$ values for 2: $-1129.5 \pm$ 9.2 (eq. 9), $-1128.0 \pm 5.7$ (eq. 10) and $-1128.3 \pm 2.2 \mathrm{~kJ} \cdot \mathrm{mol}^{-1}$ (eq. 11 ), where the uncertainty associated to each one of them includes the experimental uncertainties in $\Delta_{\mathrm{f}} H_{\mathrm{m}}^{0}(\mathrm{~g})$ of the corresponding reference compounds. The average of these values can be taken as $\Delta_{\mathrm{f}} H_{\mathrm{m}}^{0}(\mathbf{2}, \mathrm{g})=-1128.6 \pm 6.4 \mathrm{~kJ} \cdot \mathrm{mol}^{-1}$. Although the standard deviation of this average is only $0.8 \mathrm{~kJ} \cdot \mathrm{mol}^{-1}$, the uncertainty associated is a combined uncertainty of the mean which includes to the individual uncertainties.

We now may ask if the value, $\Delta_{\mathrm{f}} H_{\mathrm{m}}^{0}(\mathbf{2}, \mathrm{g})=-1128.6 \pm 6.4 \mathrm{~kJ} \cdot \mathrm{mol}^{-1}$, is plausible. It is known that there are no experimental $\Delta_{\mathrm{f}} H_{\mathrm{m}}^{0}(\mathrm{~g})$ data for any other chromenochromene derivative than our tetrahydroxy species, nor for any 5,9-dihetero derivative of pyrene where recognize that species 2 could have been named as a 4,9-dioxapyrene-5,10-dionetetraol. Let us accordingly remove the four hydroxyl groups from $\mathbf{2}$ to form the alternatively named, chromeno[5,4,3-cde]chromene-5,10-dione and 4,9-dioxapyrene-5,10dione, species 3 and casually estimate $\Delta_{\mathrm{f}} H_{\mathrm{m}}^{0}(\mathbf{3}, \mathrm{g})$ is as $-1128.6+4 \times 180 \approx-410 \mathrm{~kJ} \cdot \mathrm{mol}^{-1}$, the $180 \mathrm{~kJ} \cdot \mathrm{mol}^{-1}$ chosen as the approximate enthalpy associated with a hydroxyl group on a benzene ring (Scheme 2). This value is very close those obtained, at M05-2X/6$311++\mathrm{G}(\mathrm{d}, \mathrm{p})$ level, using isodesmic reactions (see Supplementary Information, S6). Now, we recast our original question as to whether this value is reasonable. We recognize $\mathbf{3}$ is related to pyrene much as coumarin is related to naphthalene by $-\mathrm{C}(\mathrm{O})-\mathrm{O}-$ replacing $\mathrm{CH}=\mathrm{CH}-$. From NIST Database [35] we find $\Delta_{\mathrm{f}} H_{\mathrm{m}}^{0}(\mathrm{~g})$ values of pyrene and naphthalene 
are, respectively, $225.5 \pm 2.5$ and $150.6 \pm 1.5 \mathrm{~kJ} \cdot \mathrm{mol}^{-1}$, and from ref. [39] we find the corresponding value of coumarin is $-163.4 \pm 3.3 \mathrm{~kJ} \cdot \mathrm{mol}^{-1}$. The assumption of thermoneutrality of the reaction, pyrene $+2 \cdot$ coumarin $\longrightarrow 3+2 \cdot$ naphthalene, results in the desired $\Delta_{\mathrm{f}} H_{\mathrm{m}}^{0}(\mathrm{~g})$ of species 3 as $-402.5 \mathrm{~kJ} \cdot \mathrm{mol}^{-1}$. This is in encouraging agreement with the value we earlier obtained with the use of quantum chemical calculations and the enthalpy change associated with a hydroxyl group.

Another estimation recognizes species $\mathbf{3}$ as a phenyl benzoate derivative and so suggests thermoneutrality of the reaction, $2 \cdot$ phenyl benzoate + biphenyl $\longrightarrow \mathbf{3}+$ 4.benzene. Taking the $\Delta_{\mathrm{f}} H_{\mathrm{m}}^{0}$ (g) of biphenyl and benzene from NIST Database [35] and of phenyl benzoate form Pedley [36], results in the desired $\Delta_{\mathrm{f}} H_{\mathrm{m}}^{0}(\mathrm{~g})$ of species 3 as -436.5 $\mathrm{kJ} \cdot \mathrm{mol}^{-1}$. It is also comparable to the value we earlier estimated for $\mathbf{3}$ by using enthalpy change associated with the removal $\mathrm{OH}$ groups of $\mathbf{1}$.

\section{Conclusions}

In this work we report an experimental and computational study of the structural, thermochemical and thermophysical properties of gallic (1) and ellagic (2) acids. We report a reliable experimental data for:

i/ standard enthalpy of formation in the solid state at $298.15 \mathrm{~K}, \Delta_{\mathrm{f}} H_{\mathrm{m}}^{0}(\mathrm{~cd})$, of $\mathbf{1}$ as $(-985.0$ $\left.\pm 2.9 \mathrm{~kJ} \cdot \mathrm{mol}^{-1}\right)$ and 2 as $\left(-1377.9 \pm 4.7 \mathrm{~kJ} \cdot \mathrm{mol}^{-1}\right)$ determined by using static micro-bomb combustion calorimetry, 
ii/ standard enthalpy of formation in the gas phase at $298.15 \mathrm{~K}, \Delta_{\mathrm{f}} H_{\mathrm{m}}^{0}(\mathrm{~g})$ of $\mathbf{1}$ as $(-835.7 \pm$ $4.0 \mathrm{~kJ} \cdot \mathrm{mol}^{-1}$ ), obtained combining $\Delta_{\mathrm{f}} H_{\mathrm{m}}^{0}(\mathrm{~cd})$ and standard enthalpy of sublimation $\Delta_{\mathrm{cd}}^{g} H_{m}^{0}$ $\left(149.3 \pm 2.6 \mathrm{~kJ} \cdot \mathrm{mol}^{-1}\right)$ values. The last one was determined by means of Knudsen-effusion technique and differential scanning calorimetry (DSC) measurements.

The calculation methodology considered here (atomization and isodesmic-reactions, evaluated at DFT/M05-2X and composite ab initio $\mathrm{Gn}(\mathrm{n}=3,4)$ theories), confirmed the excellent consistency between experimental and estimated $\Delta_{\mathrm{f}} H_{\mathrm{m}}^{0}(\mathrm{~g})$ values of $\mathbf{1}$. The isodesmic-reactions methodology also allowed us to determine the $\Delta_{\mathrm{f}} H_{\mathrm{m}}^{0}(\mathrm{~g})$ of $\mathbf{2}$, as being of $-1128.6 \pm 6.4 \mathrm{~kJ} \cdot \mathrm{mol}^{-1}$. It is a plausible value that can be used to estimate $\Delta_{\mathrm{f}} H_{\mathrm{m}}^{0}(\mathrm{~g})$ of chromenochromene derivatives only considering enthalpy changes associated to the removal or introduction of $\mathrm{OH}$ groups.

\section{Acknowledgments}

J.Z.D acknowledges the support funding to IQFR-CSIC (Spain) and peruvian CONCYTEC (INNÓVATE PERÚ, ECIP-1-P-030-14 grant). We wish to thank Fundação para a Ciência e Tecnologia (FCT), Lisbon, Portugal, and the European Social Fund (ESF) for their financial support to CIQUP, University of Porto (Projects: PEst-C/QUI/UI0081/2011, FCUP-CIQ-UP-NORTE-07-0124-FEDER-000065). Carlos F.R.A.C.L. thanks for is Research Grant SFRH/BPD/77972/2011.

\section{Supplementary Information Available}

There is supplementary information available with the next detailed results:

S1. DSC measurements: Fusion point and molar heat capacities. 
S2. Combustion calorimetry.

S3. Knudsen Effusion technique.

S4. Computational results.

S5. Thermochemical properties of pyrogallol.

S6. Thermochemical properties of chromeno[5,4,3-cde]chromene-5,10-dione (3).

\section{References}

[1] B. Badhani, N. Sharma, R. Kakkar, RSC Adv. 5 (2015) 27540-27557

[2] J. Jayamani, G. Shanmugam, Eur. J. Med. Chem. 85 (2014) 352-358.

[3] G.S. Esther, A.J. Manonmani, Int. J. Drug Dev. \& Res. 6 (2014) 248-258.

[4] S. Goriparti, M.N.K. Harish, S. Sampath, Chem. Commun. 49 (2013) 7234-7236.

[5] F.M.F. Roleira, E.J. Tavares-da-Silva, C.L. Varela, S.C. Costa, T. Silva, J. Garrido, F. Borges, Food Chem. 183 (2015) 235-258.

[6] M. Larrosa, M.T. García-Conesa, J.C. Espín, F.A. Tomás-Barberán, Mol. Aspects Med. 31 (2010) 513-539.

[7] B. Badhani, R. Kakkar, Struct Chem 29 (2018) 359-373.

[8] Y. Chen, H. Xiao, J. Zheng, G. Liang, PLOS One (2015) 1-20.

[9] A. Galano, M.F. Marquez,\$A. Pérez-González, Chem. Res. Toxicol. 27 (2014) 904-918.

[10] J. Zhang, Y. Xiong, B. Peng, H. Gao, Z. Zhou, Comput. Theor. Chem. 963 (2011) 148-153.

[11] J.Z. Dávalos, M.V. Roux, Meas. Sci.Technol. 11 (2000) 1421-1425.

[12] M.V. Roux, P. Jiménez, J.Z. Dávalos, M. Temprado, J.F. Liebman, J. Chem. Thermodyn. 35 (2003) 803-811.

[13] R. Sabbah, J.A.G. Perez, Thermochim. Acta 297 (1997) 17-32. 
[14] W.N. Hubbard, D.W. Scott, G. Waddington, in: F.D. Rossini (Ed.), Experimental Thermochemistry, Interscience, New York, 1956 (Chapter 5).

[15] W.D Good, N.K. Smith, J. Chem. Eng. Data 14 (1969) 102-106.

[16] M.E. Wieser, N. Holden, T.B. Coplen, J.K. Böhlke, M. Berglund, W.A. Brand, P. De Bièvre, M. Gröning, R.D. Loss, J. Meija, T. Hirata, T. Prohaska, R. Schoenberg, G. O'Connor, T. Walczyk, S. Yoneda, X.-K. Zhu, Pure Appl. Chem. 85 (2013) 1047-1078. [17] L.M.N.B.F Santos, L.M.S.S. Lima, C.F.A.C. Lima, F.D. Magalhães, M.C. Torres, B. Schröder, M.A.V. Ribeiro da Silva, J. Chem. Thermodyn. 43 (2011) 834-843.

[18] Y. Zhao, N.E. Schultz, D.G. Truhlar, J. Chem. Theor. Comput. 2 (2006) 364-382.

[19] L.A. Curtiss, K. Raghavachari, P.C. Redfern, V. Rassolov, J.A. Pople, J. Chem. Phys. 109 (1998) 7764-7776.

[20] L.A Curtiss, P.C. Redfern, K. Raghavachari, J. Chem. Phys. 126 (2007) .

[21] A. Nicolaides, A. Rauk, M.N. Glukhovtsev, L. Radom, J. Chem. Phys. 100 (1996) 17460-17464.

[22] J.Z. Dávalos, A. Guerrero, A.C. Valderrama-Negrón, V. Romero, A. F. Lago, J. Chem. Thermodyn. 97 (2016) 315-321.

[23] F.L. Mota, A.J. Queimada, S.P. Pinho, E.A. Macedo, Ind. Eng. Chem. Res. 47 (2008) $5182-5189$.

[24] R. Bogel-Łukasik, L.M. N. Gonçalves, E. Bogel-Łukasik, Green Chem. 12 (2010) $1947-1953$

[25] M. Rabiei, H. Sabahi, A. Hossein Rezayan, App. Clay Sci. 119 (2016) 236-242.

[26] Y. Neo, S. Ray, J. Jin, M. Gizdavic-Nikolaidis, M.K. Nieuwoudt, D. Liu, S.Y. Quek, Food Chem. 136 (2013) 1013-1021.

[27] M.S. Masoud, S.S. Hagagg, A.E. Ali, N.M. Nasr, J. Mol. Struct. 1014 (2012) 17-25. 
[28] Y. Li, X. Zhao, Y. Zu, Y. Zhang, Y. Ge, Ch. Zhong, W. Wu, Int. J. Pharm. 486 (2015) $207-216$

[29] V. Arulmozhi, K. Pandian, S. Mirunalini, Colloids Surf. B 110 (2013) 313-320

[30] M.Z. Hussein, S.H.A. Ali, Z. Zainal, M.N. Hakim, Int. J. Nanomed. 6 (2011) 13731383.

[31] CODATA. Recommended key values for thermodynamics, 1975. J. Chem.

Thermodyn. 8 (1976) 603-605.

[32] G.A. Lobanov, L.P. Karmanova, Izv. Vyssh. Uchebn. Zaved., Khim. Khim. Tekhnol., 14 (1971) 865-867.

[33] B. Badhani, R. Kakkar, Struct Chem 28 (2017) 1789-1802

[34] Z. Marković, D. Milenković, J. Đorović, J.M. Dimitrić Marković, B. Lučić, D. Amić, Monatsh Chem 144 (2013) 803-812.

[35] NIST Chemistry Webbook, in: P.J. Linstrom, W.G. Mallard (Eds.), NIST Standard Reference Database Number 69, National Institute of Standards and Technology: Gaithersburg, MD, 20899 (Retrieved December 22, 2017).

[36] J.B. Pedley Thermochemical Data and Structures of Organic Compounds; Thermodynamics Research Center: College Station, TX, 1994.

[37] M.J.S. Monte, M.V. Gonçalves, M.D.M.C. Ribeiro da Silva, J. Chem. Eng. Data 55 (2010) 2246-2251.

[38] M.D.M.C. Ribeiro da Silva, M.A.V. Ribeiro da Silva, G. Pilcher, J. Chem.

Thermodynamics 18 (1984) 295-300.

[39] M.A.R. Matos, C.C.S. Sousa, M.S. Miranda, V.M.F. Morais, J.F. Liebman, J. Phys. Chem. B 113 (2009) 11216-11221. 


\section{Figures and Tables}

TABLE 1. Provenance and purity of gallic (1) and ellagic (2) acids

\begin{tabular}{lccccc}
\hline Chemical Name & Provenance & CAS & $\begin{array}{c}\text { Mole fraction } \\
\text { number }\end{array}$ & $\begin{array}{c}\text { Purification } \\
\text { method }\end{array}$ & Analysis method \\
\hline Gallic acid (1) & Sigma-Aldrich & $149-91-7$ & $0.99^{\mathrm{c}}(>0.985)$ & None & $\mathrm{GC}^{\mathrm{c}}$ \\
Ellagic acid (2) & Sigma-Aldrich & $476-66-4$ & $(\geq 0.95),>0.98^{\mathrm{b}}$ & None & $\left(\mathrm{HPLC}^{\mathrm{a}}, \mathrm{NMR}^{\mathrm{b}}\right.$ \\
\hline
\end{tabular}

${ }^{a}$ Between brackets purity based on information provided by the supplier Sigma-Aldrich. ${ }^{\mathrm{b}}$ This work, ${ }^{1} \mathrm{H}$ and ${ }^{13} \mathrm{C}$ NMR spectra of ellagic acid were recorded in DMSO-d6 at $T=$ 333.15 K (no impurities were detected by NMR). ${ }^{\mathrm{c}}$ Gas-chromatography (Agilent/Varian 450) using a HP-5 column. 
TABLE 2. Typical combustion experiments for $\mathbf{1}$ and $\mathbf{2}$ at $T=298.15 \mathrm{~K}^{\mathrm{a}}$

\begin{tabular}{|c|c|c|}
\hline & Gallic acid (1) & Ellagic acid (2) \\
\hline$m$ (compound) /g & 0.10080 & 0.07904 \\
\hline$m^{\prime}$ (vaseline) $/ \mathrm{g}$ & 0.01568 & 0.01928 \\
\hline$m^{\prime \prime}$ (fuse) /g & 0.00054 & 0.00046 \\
\hline$\Delta T_{\mathrm{c}} / \mathrm{K}=\left(T_{\mathrm{f}}-T_{\mathrm{i}}+\Delta T_{\text {corr }}\right) / \mathrm{K}$ & 1.0889 & 1.0470 \\
\hline$\varepsilon$ (calor) $\left(-\Delta T_{\mathrm{c}}\right) / \mathrm{kJ}^{\mathrm{b}}$ & -2.29236 & -2.20427 \\
\hline$\varepsilon$ (cont.) $\left(-\Delta T_{\mathrm{c}}\right) / \mathrm{kJ}^{\mathrm{c}}$ & -0.00110 & -0.00104 \\
\hline$\Delta U_{\mathrm{ign}} / \mathrm{kJ}{ }^{\mathrm{d}}$ & 0.0004 & 0.0004 \\
\hline$\Delta U_{\mathrm{dec}}\left(\mathrm{HNO}_{3}\right) / \mathrm{kJ}^{\mathrm{e}}$ & 0.00029 & 0.00024 \\
\hline$\Delta U($ corr. to std. States $) / \mathrm{kJ}^{\mathrm{f}}$ & 0.00218 & 0.00200 \\
\hline$-m^{\prime} \Delta_{\mathrm{c}} u^{\mathrm{o}}$ (vaseline) / kJ & 0.7226 & 0.8884 \\
\hline$-m^{\prime \prime} \Delta_{\mathrm{c}} u^{\mathrm{o}}$ (fuse) $/ \mathrm{kJ}$ & 0.0095 & 0.0081 \\
\hline$\Delta_{\mathrm{c}} u^{0}($ compound $) / \mathrm{kJ} \cdot \mathrm{g}^{-1}$ & -15.4606 & -16.5245 \\
\hline$<\Delta_{\mathrm{c}} u^{0}(298.15 \mathrm{~K})>/ \mathrm{kJ} \cdot \mathrm{g}^{-1}$ & $-15.4568 \pm 0.0074^{\mathrm{g}}$ & $-16.5286 \pm 0.0063^{g}$ \\
\hline
\end{tabular}

${ }^{\mathrm{a}}$ For a definition of the symbols see Ref. $14 .{ }^{\mathrm{b}} \varepsilon$ (calor), energy equivalent of the whole system excluding the heat capacity of the bomb. ${ }^{\mathrm{c}} \varepsilon$ (cont.), energy equivalent of the contents of the bomb $\varepsilon$ (cont.) $\left(-\Delta T_{c}\right)=\varepsilon^{i}($ cont. $)\left(T^{\mathrm{i}}-298.15 \mathrm{~K}\right)+\varepsilon^{\mathrm{i}}$ (cont. $)\left(298.15 \mathrm{~K}-T^{\mathrm{f}}+\right.$ $\Delta T_{\text {corr. }} .{ }^{\mathrm{d}}$ Experimental energy of ignition. ${ }^{\mathrm{e}}$ Experimental energy of formation of nitric acid. ${ }^{\mathrm{f}} \Delta U$ (corr. to std. states) is the correction to standard state. ${ }^{\mathrm{g}}$ Uncertainty associated is the standard uncertainty of the mean for five experiments. 
TABLE 3. Experimental determination of standard $\left(p^{0}=10^{5} \mathrm{~Pa}\right)$ molar enthalpies of: combustion, formation (in the condensed and gaseous states) and sublimation, at $T=298.15$ $\mathrm{K}$. All values are given in $\mathrm{kJ} \cdot \mathrm{mol}^{-1}$.

\begin{tabular}{ccccc}
\hline & $\Delta_{\mathrm{c}} H_{\mathrm{m}}^{0}(\mathrm{~cd})^{\mathrm{a}}$ & $\Delta_{\mathrm{f}} H_{\mathrm{m}}^{0}(\mathrm{~cd})^{\mathrm{a}}$ & $\Delta_{\mathrm{cd}}^{g} H_{m}^{0 \mathrm{~b}}$ & $\Delta_{\mathrm{f}} H_{\mathrm{m}}^{0}(\mathrm{~g})$ \\
\hline $\mathbf{1}$, gallic acid & $-2627.1 \pm 2.8$ & $-985.0 \pm 2.9$ & $149.3 \pm 2.6$ & $-835.7 \pm 4.0$ \\
$\mathbf{2}$, ellagic acid & $-4988.8 \pm 4.3$ & $-1377.9 \pm 4.7$ & & \\
\hline
\end{tabular}

${ }^{\text {a }}$ Uncertainties associated are combined expanded uncertainties of the mean $(0.95$ level of confidence) and include the contributions from the calibration with benzoic acid and from the combustion energy of the vaseline. ${ }^{b}$ Associated uncertainty calculated by applying the propagation of uncertainty to equation (5), the uncertainty in $\Delta_{\mathrm{cd}}^{g} H_{\mathrm{m}}^{0}\left(T_{\mathrm{m}}\right)$ was calculated from the uncertainty of the slope respecting the $\ln p=f(1 / T)$ linear regression. 


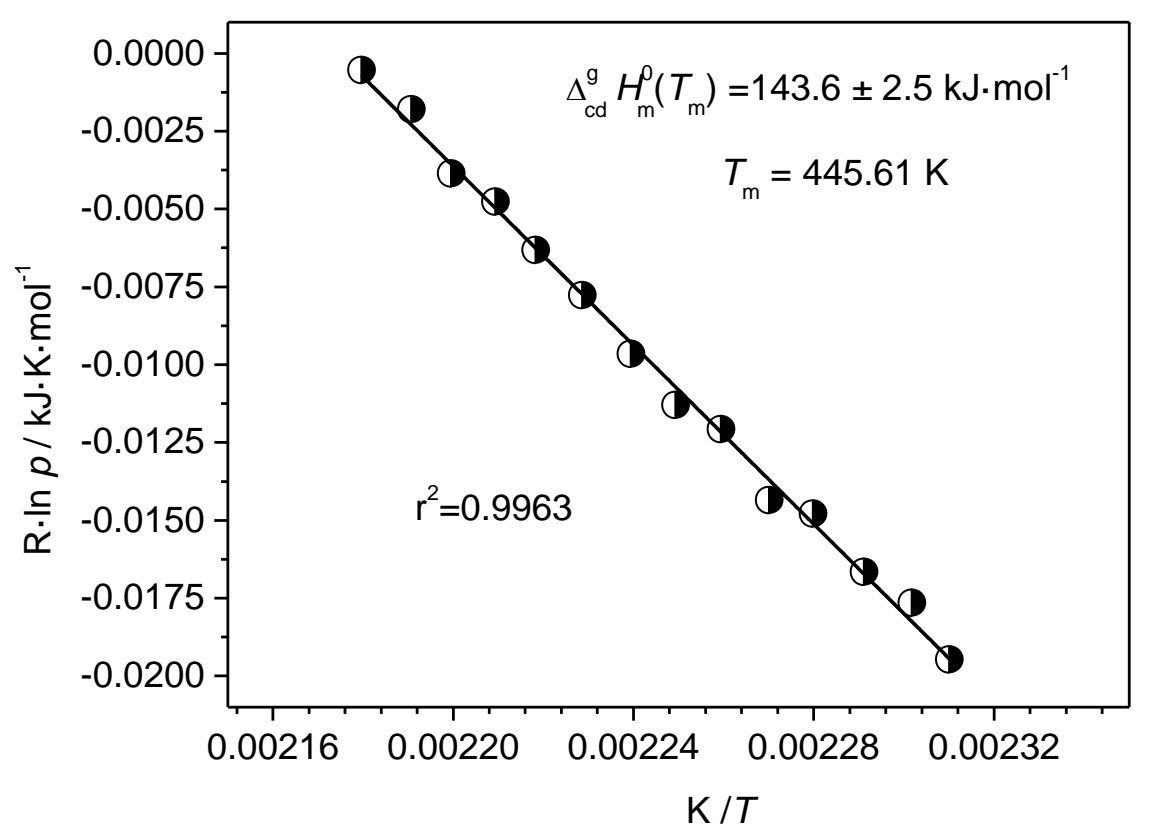

Figure 1. Plot of $\mathrm{R} \cdot \ln p$ against $1 / \mathrm{T}$ for gallic acid (1). 


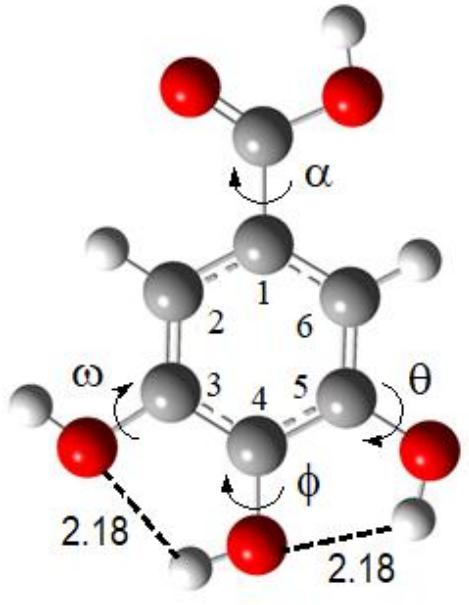

$\theta=\omega=\phi=\alpha=0$

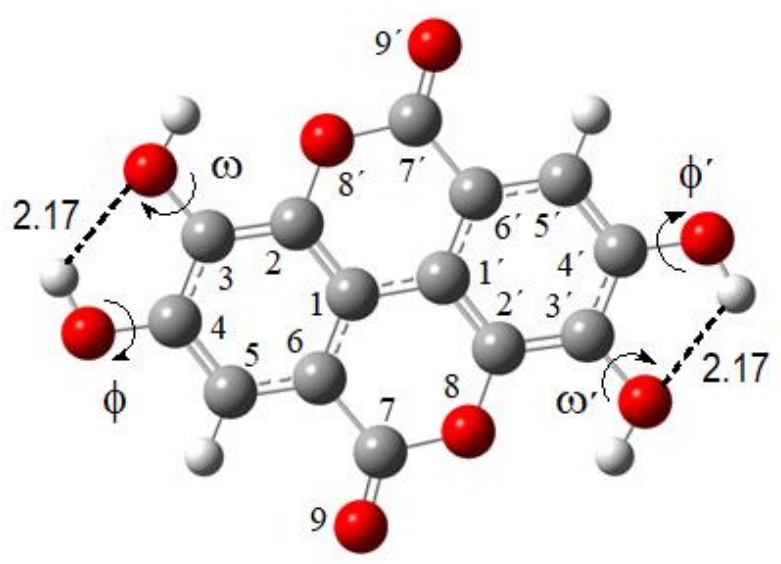

$\theta=\theta^{\prime}=\omega=\omega^{\prime}=\phi=\phi^{\prime}=0$

Figure 2. Molecular geometry of the most stable rotamers of $\mathbf{1}$ (left) and $\mathbf{2}$ (right) optimized at M05-2X/6-311++G(d,p) level of theory. Angles in degrees and distances in $\AA$. 
<smiles>O=C(O)c1cc(O)c(O)c(O)c1</smiles>

1<smiles>O=c1oc2c(O)c(O)cc3c(=O)oc4c(O)c(O)cc1c4c23</smiles>

2

Scheme 1. Molecular structure of gallic (1) and ellagic (2) acids

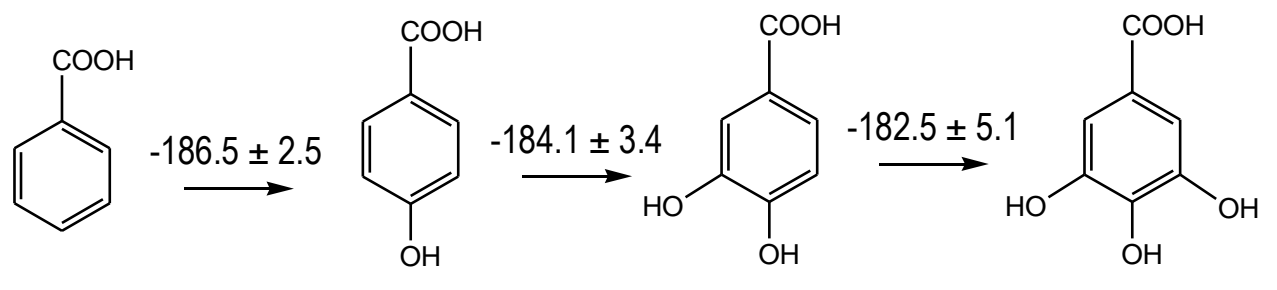

benzoic acid (BA) 4-hydroxy-BA 3,4-dihydroxy-BA gallic acid (1)

$\longrightarrow \stackrel{-179.3 \pm 0.9}{\longrightarrow}$

benzene<smiles>Oc1ccccc1</smiles>

phenol<smiles>Oc1ccccc1O</smiles>

catechol<smiles>Oc1cccc(O)c1O</smiles>

pyrogallol

Scheme 2. Enthalpic decreases, $\Delta \Delta_{\mathrm{f}} H_{\mathrm{m}}^{0}(\mathrm{~g})$, associated to the introduction of $\mathrm{OH}$ groups in benzoic acid and benzene molecules. All the values are given in $\mathrm{kJ} \cdot \mathrm{mol}^{-1}$. $\Delta_{\mathrm{f}} H_{\mathrm{m}}^{0}(4-\mathrm{hydroxy}-\mathrm{BA}, \mathrm{g})=-480.5 \pm 1.2 \mathrm{~kJ} \cdot \mathrm{mol}^{-1}[35], \Delta_{\mathrm{f}} H_{\mathrm{m}}^{0}($ pyrogallol, $\mathrm{g})=-434.2 \pm 1.1$ $\mathrm{kJ} \cdot \mathrm{mol}^{-1}$ [38]. 


\title{
Supplementary Information for
}

\section{Thermochemical and Structural Studies of Gallic and Ellagic}

\author{
Acids \\ Juan Z. Dávalos ${ }^{1 *}$, Carlos F. R. A. C. Lima ${ }^{2,3}$, Luís M. N. B. F. Santos ${ }^{2}$, Violeta L. Romero ${ }^{4}$ and \\ Joel F. Liebman ${ }^{5}$ \\ ${ }^{1}$ Instituto de Química-Física “Rocasolano”, CSIC, Serrano 119, 28006, Madrid, Spain. \\ ${ }^{2}$ Centro de Investigação em Química, Departamento de Química e Bioquímica, Faculdade \\ de Ciências da Universidade do Porto, Rua do Campo Alegre, 687, P-4169-007 Porto, \\ Portugal \\ ${ }^{3}$ Department of Chemistry \& QOPNA, University of Aveiro, Aveiro 3810-193, Portugal \\ ${ }^{4}$ Facultad de Ingeniería Industrial y de Sistemas, Universidad Nacional Federico Villarreal, \\ Av. Colonial 450, Lima 01, Perú \\ ${ }^{5}$ Department of Chemistry and Biochemistry, University of Maryland, Baltimore County, \\ Baltimore, MD 21250, USA
}

* Corresponding author:

Tel.: +34919619400

E-mail address: jdavalos@iqfr.csic.es 


\section{Topics}

S1. DSC measurements: Fusion point and molar heat capacities.

S2. Combustion calorimetry.

S3. Knudsen Effusion technique.

S4. Computational results.

S5. Thermochemical properties of pyrogallol.

S6. Thermochemical properties of chromeno[5,4,3-cde]chromene-5,10-dione (3). 


\section{S1. DSC measurements: Fusion point and molar heat capacities.}

DSC (Perkin Elmer Pyris 1) was used in the thermal stability study and for the measurement of the heat capacities. The samples were weighed (2-5mg) with a Mettler AT21 microbalance $( \pm 1 \mu \mathrm{g})$ and hermetically sealed in aluminum pans. The DSC thermograms were recorded with a heating rate of $0.17 \mathrm{~K} \cdot \mathrm{s}^{-1}$. The molar heat capacities at constant pressure, $C_{p, \mathrm{~m}}^{0}$, were obtained following the "scanning method" previously described in the literature $\left[{ }^{1}\right]$, using synthetic sapphire ( $\alpha$-aluminium oxide) as reference material. The experimental data, reported in Table S1, are depicted in Fig. S1.

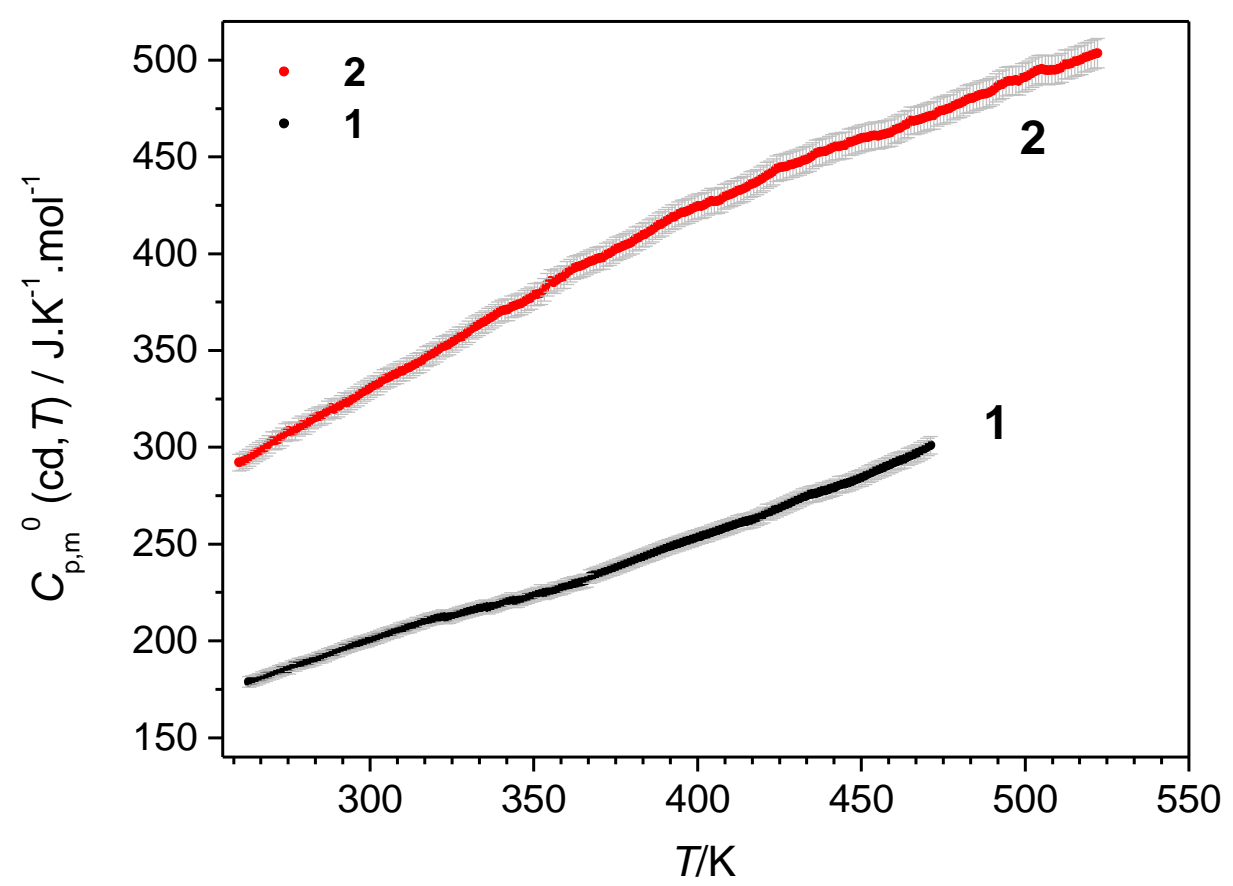

Figure S1. $C_{p, \mathrm{~m}}^{0}$ vs temperature of gallic (1) and ellagic (2) acids.

[1] a) M.V. Roux, M. Temprado, P. Jiménez, R. Guzmán-Mejía, E. Juaristi, J.S. Chickos, Thermochim. Acta 406 (2003) 9. (b) S.C. Mraw, D.F. Naas, J. Chem. Thermodyn. 11 (1979) 567. (c) M.J. O’Neill, Anal. Chem. 8 (1969) 1331. (d) J.E. Callanan, S.A. Sullivan, Rev. Sci. Instrum. 57 (1986) 2584. 
Table S1. The molar heat capacities at constant pressure $(p=0.1 \mathrm{MPa}), C_{p, \mathrm{~m}}^{0}(\mathrm{~cd}, T)$, of gallic $(\mathbf{1})$ and ellagic (2) acids. The standard uncertainties are reported. ${ }^{\mathrm{a}}$

\begin{tabular}{|c|c|c|c|c|c|c|c|c|c|c|c|}
\hline \multicolumn{6}{|c|}{ Gallic acid (1) } & \multicolumn{6}{|c|}{ Ellagic acid (2) } \\
\hline$T / \mathrm{K}$ & $\begin{array}{l}C_{p, \mathrm{~m}}^{0}(\mathrm{~cd}, T) \\
/ \mathrm{J} \cdot \mathrm{K}^{-1} \cdot \mathrm{mol}^{-1}\end{array}$ & $T / \mathrm{K}$ & $\begin{array}{l}C_{p, \mathrm{~m}}^{0}(\mathrm{~cd}, T) \\
/ \mathrm{J} \cdot \mathrm{K}^{-1} \cdot \mathrm{mol}^{-1}\end{array}$ & $T / \mathrm{K}$ & $\begin{array}{l}C_{p, \mathrm{~m}}^{0}(\mathrm{~cd}, T) \\
/ \mathrm{J} \cdot \mathrm{K}^{-1} \cdot \mathrm{mol}^{-1}\end{array}$ & $T / \mathrm{K}$ & $\begin{array}{l}C_{p, \mathrm{~m}}^{0}(\mathrm{~cd}, T) \\
/ \mathrm{J} \cdot \mathrm{K}^{-1} \cdot \mathrm{mol}^{-1}\end{array}$ & $T / \mathrm{K}$ & $\begin{array}{l}C_{p, \mathrm{~m}}^{0}(\mathrm{~cd}, T) \\
/ \mathrm{J} \cdot \mathrm{K}^{-1} \cdot \mathrm{mol}^{-1}\end{array}$ & $T / \mathrm{K}$ & $\begin{array}{l}C_{p, \mathrm{~m}}^{0}(\mathrm{~cd}, T) \\
/ \mathrm{J} \cdot \mathrm{K}^{-1} \cdot \mathrm{mol}^{-1}\end{array}$ \\
\hline 263.15 & 178.80 & 351.15 & 224.44 & 439.15 & 277.72 & 260.15 & 292.07 & 348.15 & 376.31 & 436.15 & 451.79 \\
\hline 264.15 & 179.31 & 352.15 & 225.58 & 440.15 & 278.23 & 261.15 & 292.68 & 349.15 & 377.02 & 437.15 & 452.39 \\
\hline 265.15 & 179.82 & 353.15 & 224.69 & 441.15 & 278.83 & 262.15 & 293.58 & 350.15 & 378.82 & 438.15 & 452.69 \\
\hline 266.15 & 180.50 & 354.15 & 225.11 & 442.15 & 279.51 & 263.15 & 294.64 & 351.15 & 379.03 & 439.15 & 452.99 \\
\hline 267.15 & 181.18 & 355.15 & 225.75 & 443.15 & 280.61 & 264.15 & 295.85 & 352.15 & 379.54 & 440.15 & 453.90 \\
\hline 268.15 & 181.86 & 356.15 & 226.47 & 444.15 & 280.87 & 265.15 & 297.06 & 353.15 & 381.35 & 441.15 & 454.71 \\
\hline 269.15 & 182.54 & 357.15 & 226.90 & 445.15 & 281.12 & 266.15 & 297.97 & 354.15 & 383.99 & 442.15 & 455.32 \\
\hline 270.15 & 183.05 & 358.15 & 227.28 & 446.15 & 281.63 & 267.15 & 298.87 & 355.15 & 385.91 & 443.15 & 455.41 \\
\hline 271.15 & 183.73 & 359.15 & 227.92 & 447.15 & 282.23 & 268.15 & 299.93 & 356.15 & 385.30 & 444.15 & 455.71 \\
\hline 272.15 & 184.41 & 360.15 & 228.68 & 448.15 & 283.16 & 269.15 & 301.59 & 357.15 & 386.51 & 445.15 & 456.02 \\
\hline 273.15 & 184.92 & 361.15 & 229.15 & 449.15 & 283.84 & 270.15 & 303.41 & 358.15 & 387.62 & 446.15 & 457.53 \\
\hline 274.15 & 185.77 & 362.15 & 229.70 & 450.15 & 284.18 & 271.15 & 303.41 & 359.15 & 388.02 & 447.15 & 457.83 \\
\hline 275.15 & 185.60 & 363.15 & 229.83 & 451.15 & 285.04 & 272.15 & 304.01 & 360.15 & 390.04 & 448.15 & 458.43 \\
\hline 276.15 & 186.96 & 364.15 & 230.21 & 452.15 & 286.14 & 273.15 & 305.37 & 361.15 & 391.30 & 449.15 & 459.04 \\
\hline 277.15 & 187.30 & 365.15 & 230.81 & 453.15 & 286.82 & 274.15 & 307.49 & 362.15 & 392.55 & 450.15 & 459.64 \\
\hline 278.15 & 188.15 & 366.15 & 231.19 & 454.15 & 287.67 & 275.15 & 308.39 & 363.15 & 393.10 & 451.15 & 459.94 \\
\hline
\end{tabular}




\begin{tabular}{|c|c|c|c|c|c|c|c|c|c|c|c|}
\hline 279.15 & 188.49 & 367.15 & 233.29 & 455.15 & 288.44 & 276.15 & 308.09 & 364.15 & 393.50 & 452.15 & 460.20 \\
\hline 280.15 & 189.00 & 368.15 & 233.91 & 456.15 & 289.03 & 277.15 & 308.54 & 365.15 & 394.20 & 453.15 & 460.85 \\
\hline 281.15 & 189.34 & 369.15 & 234.54 & 457.15 & 289.80 & 278.15 & 310.36 & 366.15 & 395.10 & 454.15 & 461.14 \\
\hline 282.15 & 189.85 & 370.15 & 234.94 & 458.15 & 290.56 & 279.15 & 311.57 & 367.15 & 396.00 & 455.15 & 460.85 \\
\hline 283.15 & 190.36 & 371.15 & 235.60 & 459.15 & 291.24 & 280.15 & 311.26 & 368.15 & 396.50 & 456.15 & 461.30 \\
\hline 284.15 & 191.21 & 372.15 & 236.24 & 460.15 & 292.18 & 281.15 & 312.62 & 369.15 & 397.30 & 457.15 & 461.76 \\
\hline 285.15 & 191.55 & 373.15 & 236.91 & 461.15 & 292.86 & 282.15 & 314.29 & 370.15 & 397.80 & 458.15 & 462.11 \\
\hline 286.15 & 192.24 & 374.15 & 237.55 & 462.15 & 293.20 & 283.15 & 315.19 & 371.15 & 398.00 & 459.15 & 462.61 \\
\hline 287.15 & 193.09 & 375.15 & 238.16 & 463.15 & 293.80 & 284.15 & 315.95 & 372.15 & 399.50 & 460.15 & 463.82 \\
\hline 288.15 & 193.60 & 376.15 & 238.86 & 464.15 & 294.99 & 285.15 & 316.25 & 373.15 & 400.10 & 461.15 & 464.57 \\
\hline 289.15 & 194.28 & 377.15 & 239.45 & 465.15 & 295.67 & 286.15 & 317.16 & 374.15 & 401.20 & 462.15 & 465.08 \\
\hline 290.15 & 194.79 & 378.15 & 240.16 & 466.15 & 296.35 & 287.15 & 318.97 & 375.15 & 402.50 & 463.15 & 466.38 \\
\hline 291.15 & 195.64 & 379.15 & 240.81 & 467.15 & 297.03 & 288.15 & 320.33 & 376.15 & 403.10 & 464.15 & 467.05 \\
\hline 292.15 & 196.32 & 380.15 & 241.44 & 468.15 & 297.96 & 289.15 & 319.72 & 377.15 & 403.80 & 465.15 & 468.71 \\
\hline 293.15 & 197.00 & 381.15 & 242.11 & 469.15 & 298.90 & 290.15 & 320.48 & 378.15 & 404.50 & 466.15 & 468.50 \\
\hline 294.15 & 197.51 & 382.15 & 242.78 & 470.15 & 300.18 & 291.15 & 321.84 & 379.15 & 405.30 & 467.15 & 469.00 \\
\hline 295.15 & 198.19 & 383.15 & 243.42 & 471.15 & 301.03 & 292.15 & 323.35 & 380.15 & 406.12 & 468.15 & 469.50 \\
\hline 296.15 & 198.70 & 384.15 & 244.06 & & & 293.15 & 323.05 & 381.15 & 407.60 & 469.15 & 470.10 \\
\hline 297.15 & 199.38 & 385.15 & 244.70 & & & 294.15 & 324.26 & 382.15 & 408.20 & 470.15 & 470.80 \\
\hline 298.15 & 199.55 & 386.15 & 245.37 & & & 295.15 & 325.47 & 383.15 & 409.50 & 471.15 & 471.20 \\
\hline 299.15 & 200.06 & 387.15 & 246.02 & & & 296.15 & 326.40 & 384.15 & 410.10 & 472.15 & 471.50 \\
\hline
\end{tabular}




\begin{tabular}{|c|c|c|c|c|c|c|c|c|c|}
\hline 300.15 & 200.57 & 388.15 & 246.65 & 297.15 & 327.73 & 385.15 & 411.31 & 473.15 & 472.94 \\
\hline 301.15 & 201.25 & 389.15 & 247.32 & 298.15 & 328.85 & 386.15 & 412.22 & 474.15 & 473.85 \\
\hline 302.15 & 201.76 & 390.15 & 248.01 & 299.15 & 329.64 & 387.15 & 413.52 & 475.15 & 474.15 \\
\hline 303.15 & 202.44 & 391.15 & 248.58 & 300.15 & 330.70 & 388.15 & 414.82 & 476.15 & 474.75 \\
\hline 304.15 & 203.12 & 392.15 & 249.14 & 301.15 & 331.91 & 389.15 & 415.43 & 477.15 & 475.05 \\
\hline 305.15 & 203.80 & 393.15 & 249.71 & 302.15 & 332.12 & 390.15 & 416.64 & 478.15 & 476.26 \\
\hline 306.15 & 204.31 & 394.15 & 250.27 & 303.15 & 333.63 & 391.15 & 417.54 & 479.15 & 477.17 \\
\hline 307.15 & 204.65 & 395.15 & 250.84 & 304.15 & 334.99 & 392.15 & 418.85 & 480.15 & 477.47 \\
\hline 308.15 & 205.33 & 396.15 & 251.40 & 305.15 & 335.69 & 393.15 & 419.15 & 481.15 & 478.38 \\
\hline 309.15 & 206.18 & 397.15 & 251.97 & 306.15 & 336.45 & 394.15 & 420.36 & 482.15 & 479.59 \\
\hline 310.15 & 206.70 & 398.15 & 252.44 & 307.15 & 337.53 & 395.15 & 421.26 & 483.15 & 480.19 \\
\hline 311.15 & 207.04 & 399.15 & 253.11 & 308.15 & 338.02 & 396.15 & 421.57 & 484.15 & 480.39 \\
\hline 312.15 & 207.38 & 400.15 & 253.68 & 309.15 & 339.27 & 397.15 & 422.17 & 485.15 & 481.19 \\
\hline 313.15 & 208.23 & 401.15 & 254.24 & 310.15 & 339.49 & 398.15 & 423.08 & 486.15 & 482.00 \\
\hline 314.15 & 208.91 & 402.15 & 254.81 & 311.15 & 340.77 & 399.15 & 423.98 & 487.15 & 482.31 \\
\hline 315.15 & 209.08 & 403.15 & 255.10 & 312.15 & 341.16 & 400.15 & 424.59 & 488.15 & 482.61 \\
\hline 316.15 & 209.76 & 404.15 & 255.93 & 313.15 & 342.26 & 401.15 & 424.59 & 489.15 & 483.31 \\
\hline 317.15 & 210.61 & 405.15 & 256.50 & 314.15 & 343.30 & 402.15 & 425.19 & 490.15 & 484.21 \\
\hline 318.15 & 211.12 & 406.15 & 257.08 & 315.15 & 343.78 & 403.15 & 426.40 & 491.15 & 485.63 \\
\hline 319.15 & 211.46 & 407.15 & 257.65 & 316.15 & 345.03 & 404.15 & 427.31 & 492.15 & 486.93 \\
\hline
\end{tabular}




\begin{tabular}{|c|c|c|c|c|c|c|c|c|c|}
\hline 320.15 & 211.80 & 408.15 & 258.22 & 317.15 & 346.85 & 405.15 & 427.00 & 493.15 & 487.54 \\
\hline 321.15 & 212.14 & 409.15 & 258.78 & 318.15 & 347.50 & 406.15 & 427.31 & 494.15 & 488.84 \\
\hline 322.15 & 212.99 & 410.15 & 259.34 & 319.15 & 348.30 & 407.15 & 427.91 & 495.15 & 489.26 \\
\hline 323.15 & 211.97 & 411.15 & 259.92 & 320.15 & 349.21 & 408.15 & 429.42 & 496.15 & 489.26 \\
\hline 324.15 & 212.22 & 412.15 & 260.74 & 321.15 & 350.81 & 409.15 & 430.03 & 497.15 & 489.56 \\
\hline 325.15 & 212.90 & 413.15 & 261.25 & 322.15 & 351.92 & 410.15 & 430.78 & 498.15 & 489.26 \\
\hline 326.15 & 213.59 & 414.15 & 261.59 & 323.15 & 352.53 & 411.15 & 431.39 & 499.15 & 490.77 \\
\hline 327.15 & 214.27 & 415.15 & 261.81 & 324.15 & 353.13 & 412.15 & 432.44 & 500.15 & 491.28 \\
\hline 328.15 & 214.61 & 416.15 & 262.27 & 325.15 & 354.43 & 413.15 & 432.90 & 501.15 & 492.18 \\
\hline 329.15 & 215.09 & 417.15 & 262.78 & 326.15 & 355.55 & 414.15 & 433.50 & 502.15 & 493.28 \\
\hline 330.15 & 215.60 & 418.15 & 263.53 & 327.15 & 356.86 & 415.15 & 434.56 & 503.15 & 494.19 \\
\hline 331.15 & 216.11 & 419.15 & 264.31 & 328.15 & 357.07 & 416.15 & 435.77 & 504.15 & 495.00 \\
\hline 332.15 & 216.39 & 420.15 & 265.03 & 329.15 & 358.38 & 417.15 & 436.20 & 505.15 & 495.30 \\
\hline 333.15 & 216.90 & 421.15 & 266.54 & 330.15 & 359.69 & 418.15 & 437.00 & 506.15 & 495.00 \\
\hline 334.15 & 217.47 & 422.15 & 266.57 & 331.15 & 361.39 & 419.15 & 438.20 & 507.15 & 494.70 \\
\hline 335.15 & 217.92 & 423.15 & 267.30 & 332.15 & 362.30 & 420.15 & 439.10 & 508.15 & 495.00 \\
\hline 336.15 & 217.16 & 424.15 & 268.08 & 333.15 & 363.10 & 421.15 & 440.50 & 509.15 & 495.00 \\
\hline 337.15 & 217.71 & 425.15 & 268.84 & 334.15 & 364.21 & 422.15 & 441.20 & 510.15 & 495.30 \\
\hline 338.15 & 218.35 & 426.15 & 269.59 & 335.15 & 365.02 & 423.15 & 442.30 & 511.15 & 496.00 \\
\hline 339.15 & 218.99 & 427.15 & 270.33 & 336.15 & 366.23 & 424.15 & 443.93 & 512.15 & 497.72 \\
\hline
\end{tabular}




\begin{tabular}{|c|c|c|c|c|c|c|c|c|c|}
\hline 340.15 & 219.58 & 428.15 & 271.11 & 337.15 & 367.13 & 425.15 & 444.50 & 513.15 & 497.82 \\
\hline 341.15 & 220.09 & 429.15 & 271.85 & 338.15 & 368.24 & 426.15 & 444.80 & 514.15 & 498.32 \\
\hline 342.15 & 220.69 & 430.15 & 272.62 & 339.15 & 369.55 & 427.15 & 445.10 & 515.15 & 499.23 \\
\hline 343.15 & 221.58 & 431.15 & 273.38 & 340.15 & 370.36 & 428.15 & 445.90 & 516.15 & 499.50 \\
\hline 344.15 & 220.47 & 432.15 & 274.32 & 341.15 & 370.96 & 429.15 & 446.20 & 517.15 & 500.10 \\
\hline 345.15 & 220.64 & 433.15 & 274.91 & 342.15 & 371.07 & 430.15 & 446.80 & 518.15 & 501.30 \\
\hline 346.15 & 221.55 & 434.15 & 275.59 & 343.15 & 372.48 & 431.15 & 447.30 & 519.15 & 501.80 \\
\hline 347.15 & 222.29 & 435.15 & 275.85 & 344.15 & 373.08 & 432.15 & 448.20 & 520.15 & 502.50 \\
\hline 348.15 & 222.74 & 436.15 & 276.19 & 345.15 & 373.69 & 433.15 & 448.60 & 521.15 & 503.10 \\
\hline 349.15 & 223.31 & 437.15 & 276.70 & 346.15 & 374.10 & 434.15 & 449.40 & 522.15 & 503.60 \\
\hline 350.15 & 223.76 & 438.15 & 277.38 & 347.15 & 375.31 & 435.15 & 450.58 & & \\
\hline
\end{tabular}

${ }^{\mathrm{a}}$ Uncertainties associated are, $u_{\mathrm{r}}\left(C_{p, \mathrm{~m}}^{0}\right)=0.015\left[{ }^{2}\right]$ and $u(T)=0.1 \mathrm{~K}\left[{ }^{3}\right]$.

$\left.{ }^{2}\right]$ S. Rudtsch, Thermochim. Acta 382 (2002) 17-25

$\left[{ }^{3}\right]$ E. Pella, M. Nebuloni, J. Thermal. Anal. 3 (1971) 229-246 


\section{S2. Combustion calorimetry}

Calorimetric temperatures of the micro-bomb calorimeter were measured to within \pm $1 \cdot 10^{-4} \mathrm{~K}$ by means of a $100 \mathrm{X}$ platinum resistance thermometer, using a calibrated resistance bridge (Model F300, Automatic System Laboratories) interfaced to a microcomputer programmed to calculate the adiabatic temperature change. The electrical energy for ignition was determined from the change in potential difference across a $4700 \mu \mathrm{F}$ capacitor previously charged to $13.5 \mathrm{~V}$ upon partial discharge through a platinum wire of $0.05 \mathrm{~mm}$ diameter to which a cotton thread had been tied. The energy of reaction was always referred to the final temperature of $298.15 \mathrm{~K}$.

The combustion bomb was flushed and filled with oxygen, previously freed from combustible impurities and an initial pressure of oxygen of $3.55 \mathrm{MPa}$ was used. The nitric acid content in the bomb liquid was determined by titration with $0.1 \mathrm{~mol}^{-1} \mathrm{dm}^{3} \mathrm{NaOH}(\mathrm{aq})$. The corrections for nitric acid formation were based on $-59.7 \mathrm{~kJ} \cdot \mathrm{mol}^{-1}\left[{ }^{4}\right]$ for the molar energy of formation of $0.1 \mathrm{~mol}^{-1} \cdot \mathrm{dm}^{-3} \mathrm{HNO}_{3}(\mathrm{aq})$ from $\mathrm{N}_{2}, \mathrm{O}_{2}$ and $\mathrm{H}_{2} \mathrm{O}$ (1).

$\left.{ }^{4}\right]$ D.D. Wagman, W.H. Evans, V.B. Parker, R.H. Schumm, I. Halow, S.M. Bailey, K.L. Churney, R.L.Nuttall, The NBS tables of chemical thermodynamic properties: selected values for inorganic and C1and C2 organic substances in SI units, J. Phys. Chem. Ref. Data 11 (Suppl. 2) (1982). 
TABLE S2. Results of combustion experiments of gallic (1) and ellagic (2) acids at $T=298.15 \mathrm{~K}^{\mathrm{a}}$

\begin{tabular}{|c|c|c|c|c|c|c|c|c|c|c|}
\hline \multirow[b]{2}{*}{$m$ (compound) $/ \mathrm{g}^{\mathrm{b}}$} & \multicolumn{5}{|c|}{ Gallic acid (1) } & \multicolumn{5}{|c|}{ Ellagic acid (2) } \\
\hline & 0.10456 & 0.1008 & 0.09618 & 0.10543 & 0.10507 & 0.07676 & 0.08285 & 0.07333 & 0.07904 & 0.08016 \\
\hline$m^{\prime}($ vaseline $) / \mathrm{g}^{\mathrm{b}}$ & 0.01192 & 0.01568 & 0.01247 & 0.01146 & 0.01194 & 0.01303 & 0.01374 & 0.02382 & 0.01928 & 0.01763 \\
\hline$m^{\prime \prime}$ (fuse) $/ \mathrm{g}^{\mathrm{b}}$ & 0.00056 & 0.00054 & 0.00047 & 0.00057 & 0.00059 & 0.00058 & 0.00055 & 0.00053 & 0.00046 & 0.00056 \\
\hline$\Delta T_{\mathrm{c}} / \mathrm{K}=\left(T_{\mathrm{f}}-T_{\mathrm{i}}+\Delta T_{\text {corr }}\right) / \mathrm{K}$ & 1.0335 & 1.0889 & 0.9842 & 1.0315 & 1.0374 & 0.8939 & 0.9573 & 1.1019 & 1.0470 & 1.0142 \\
\hline$\varepsilon$ (calor) $\left(-\Delta T_{\mathrm{c}}\right) / \mathrm{kJ}^{\mathrm{c}}$ & -2.17585 & -2.29236 & -2.07195 & -2.17152 & -2.18401 & -1.88192 & -2.01551 & -2.31973 & -2.20427 & -2.13520 \\
\hline$\varepsilon$ (cont.) $\left(-\Delta T_{\mathrm{c}}\right) / \mathrm{kJ}{ }^{\mathrm{d}}$ & -0.00104 & -0.00110 & -0.00098 & -0.00104 & -0.00104 & -0.00086 & -0.00094 & -0.00110 & -0.00104 & -0.00100 \\
\hline$\Delta U_{\mathrm{ign}} / \mathrm{kJ}{ }^{\mathrm{e}}$ & 0.0004 & 0.0004 & 0.0004 & 0.0004 & 0.0004 & 0.0004 & 0.0004 & 0.0004 & 0.0004 & 0.0004 \\
\hline$\Delta U_{\mathrm{dec}}\left(\mathrm{HNO}_{3}\right) / \mathrm{kJ}^{\mathrm{f}}$ & 0.00029 & 0.00029 & 0.00029 & 0.00029 & 0.00029 & 0.00018 & 0.00024 & 0.00024 & 0.00024 & 0.00018 \\
\hline$\Delta U($ corr. to std. States $) / \mathrm{kJ}^{\mathrm{g}}$ & 0.00218 & 0.00218 & 0.00201 & 0.00219 & 0.00220 & 0.00183 & 0.00199 & 0.00195 & 0.00200 & 0.00199 \\
\hline$-\mathrm{m}^{\prime} \Delta_{\mathrm{c}} u^{\mathrm{o}}($ vaseline $) / \mathrm{kJ}$ & 0.5491 & 0.7226 & 0.5746 & 0.5281 & 0.5502 & 0.60066 & 0.63328 & 1.09774 & 0.88844 & 0.80013 \\
\hline$-\mathrm{m}^{\prime \prime} \Delta_{\mathrm{c}} u^{\mathrm{o}}$ (fuse) $/ \mathrm{kJ}$ & 0.0098 & 0.0095 & 0.0082 & 0.0099 & 0.0103 & 0.01014 & 0.00953 & 0.00916 & 0.00809 & 0.00978 \\
\hline$\Delta_{\mathrm{c}} u^{0}$ (compound) $/ \mathrm{kJ} \cdot \mathrm{g}^{-1}$ & -15.4464 & -15.4606 & -15.4654 & -15.4769 & -15.4347 & -16.5386 & -16.5472 & -16.5198 & -16.5245 & -16.5130 \\
\hline$<\Delta_{\mathrm{c}} u^{0}(298.15 \mathrm{~K})>/ \mathrm{kJ} \cdot \mathrm{g}^{-1}$ & \multicolumn{5}{|c|}{$-15.4568 \pm 0.0074^{h}$} & \multicolumn{5}{|c|}{$-16.5286 \pm 0.0063^{h}$} \\
\hline
\end{tabular}


${ }^{\mathrm{a}}$ For a definition of the symbols see Ref. ${ }^{5} . T_{\mathrm{th}}=298.15 \mathrm{~K} ; V_{\mathrm{bomb}}=0.022 \mathrm{dm}^{3}$ for micro-bomb calorimeter. $p_{\text {gas }}^{\mathrm{i}}=3.04 \mathrm{MPa} .{ }^{b}$ Masses obtained from apparent mass. ${ }^{\mathrm{c}} \varepsilon$ (calor), energy equivalent of the whole system excluding the heat capacity of the bomb. ${ }^{\mathrm{d}} \varepsilon$ (cont.), energy equivalent of the contents of the bomb $\varepsilon$ (cont.) $\left(-\Delta T_{c}\right)=\varepsilon^{i}$ (cont.) $\left(T^{\mathrm{i}}-298.15 \mathrm{~K}\right)+\varepsilon^{\dot{j}}$ (cont.) $\left(298.15 \mathrm{~K}-T^{\mathrm{f}}+\Delta T_{\text {corr. }}\right) .{ }^{\mathrm{e}}$ Experimental energy of ignition. ${ }^{\mathrm{f}}$ Experimental energy of formation of nitric acid. ${ }^{\mathrm{g}} \Delta U$ (corr. to std. states) is the correction to standard state. ${ }^{\mathrm{h}}$ Uncertainty associated is the standard uncertainty of the mean for five experiments.

[5] W.N. Hubbard, D.W. Scott, G. Waddington, in: F.D. Rossini (Ed.), Experimental Thermochemistry, Interscience, New York, 1956, chapter 5. 


\section{S3. Knudsen Effusion technique.}

Table S3a. Equilibrium vapor pressures as a function of temperature for gallic acid (1), as measured by the Knudsen effusion technique.

\begin{tabular}{cc|cc}
\hline$T / \mathrm{K}^{\mathrm{a}}$ & $p / \mathrm{Pa}^{\mathrm{b}}$ & $T / \mathrm{K}^{\mathrm{a}}$ & $p / \mathrm{Pa}^{\mathrm{b}}$ \\
\hline 432.88 & 0.0961 & 446.54 & 0.3130 \\
434.44 & 0.1197 & 448.70 & 0.3927 \\
436.46 & 0.1349 & 450.78 & 0.4674 \\
438.62 & 0.1688 & 452.60 & 0.5635 \\
440.50 & 0.1779 & 454.63 & 0.6284 \\
442.58 & 0.2341 & 456.47 & 0.8057 \\
444.57 & 0.2570 & 458.78 & 0.9376 \\
\hline
\end{tabular}

${ }^{\mathrm{a}}$ Standard uncertainty is $u(T)=0.01 \mathrm{~K} .{ }^{\mathrm{b}}$ Expanded uncertainty is $U(p)=0.01 \mathrm{~Pa}$ (derived from applying the propagation of uncertainty to the Knudsen equation).

Table S3b. Experimental results obtained for 1, where A and B are from the ClausiusClapeyron equation: $\ln (p / \mathrm{Pa})=\mathrm{A}-\mathrm{B} \cdot(\mathrm{K} / T)$, and $\mathrm{B}=\Delta_{\mathrm{cd}}^{\mathrm{g}} H_{\mathrm{m}}^{0}\left(T_{\mathrm{m}}\right) / \mathrm{R} ; \mathrm{R}=8.314472 \mathrm{~J} \cdot \mathrm{K}^{-}$ ${ }^{1} \cdot \mathrm{mol}^{-1} \cdot T_{\mathrm{m}}$ is the mean temperature

\begin{tabular}{|c|c|c|c|c|c|c|}
\hline \multirow{2}{*}{ A } & B & 2 & $T_{\mathrm{m}}$ & $p\left(T_{\mathrm{m}}\right)$ & $\Delta_{\mathrm{cr}}^{\mathrm{g}} H_{\mathrm{m}}^{0}\left(T_{\mathrm{m}}\right)$ & $\Delta_{\mathrm{cr}}^{\mathrm{g}} S_{\mathrm{m}}^{0}\left(T_{\mathrm{m}}\right)$ \\
\hline & $\mathrm{K}$ & & $\mathrm{K}$ & $\mathrm{Pa}$ & $\mathrm{kJ} \cdot \mathrm{mol}^{-1}$ & $\mathrm{~J} \cdot \mathrm{K}^{-1} \cdot \mathrm{mol}^{-1}$ \\
\hline $\begin{array}{c}37.57 \pm \\
0.68^{\text {a }}\end{array}$ & $\begin{array}{c}17276 \pm \\
304^{\mathrm{b}}\end{array}$ & 0.9963 & $445.61^{\mathrm{c}}$ & $0.3016^{\mathrm{d}}$ & $143.6 \pm 2.5^{\mathrm{e}}$ & $216.7 \pm 5.7^{1}$ \\
\hline
\end{tabular}

${ }^{a}$ Uncertainty of the intercept derived from linear regression of the Clausius-Clapeyron eq. (S2). ${ }^{\mathrm{b}}$ Uncertainty of the slope derived from linear regression of the eq. (S2). ${ }^{\mathrm{c}}$ Standard uncertainty, $u(T)=0.01 \mathrm{~K} .{ }^{\mathrm{d}}$ Standard uncertainty, $u(p)=0.0050 \mathrm{~Pa}$. ${ }^{\mathrm{e}}$ Uncertainty calculated from the uncertainty of the slope. ${ }^{\mathrm{f}}$ Associated uncertainty corresponds to the uncertainty in $\Delta_{\mathrm{cd}}^{g} S_{m}\left(T_{m}, p_{m}\right)$, which was calculated by applying the propagation of uncertainty to the fo $\Delta_{\text {cd }}^{g} S_{m}\left(T_{m}, p_{m}\right)=\Delta_{\text {cd }}^{g} H_{m}\left(T_{m}, p_{m}\right) / T_{m}$ 
Table S3c. Standard molar $\left(p=p^{0}=0.1 \mathrm{MPa}\right)$ enthalpy, entropy and Gibbs energy of sublimation, at $T=298.15 \mathrm{~K}$, for gallic acid (1).

\begin{tabular}{llll}
\hline & $\Delta_{\mathrm{cr}}^{\mathrm{g}} H_{\mathrm{m}}^{0} / \mathrm{kJ} \cdot \mathrm{mol}^{-1}$ & $\Delta_{\mathrm{cr}}^{\mathrm{g}} S_{\mathrm{m}}^{0} / \mathrm{J} \cdot \mathrm{K}^{-1} \cdot \mathrm{mol}^{-1}$ & $\Delta_{\mathrm{cr}}^{\mathrm{g}} G_{\mathrm{m}}^{0} / \mathrm{kJ} \cdot \mathrm{mol}^{-1}$ \\
\hline gallic acid (1) & $149.3 \pm 2.6^{\mathrm{a}}$ & $231.5 \pm 5.9^{\mathrm{b}}$ & $80.3 \pm 3.1^{\mathrm{c}}$ \\
\hline
\end{tabular}

${ }^{a}$ Associated uncertainty calculated by applying the propagation of uncertainty to the equation (5) in the main manuscript.

${ }^{\mathrm{b}}$ Associated uncertainty corresponds to the uncertainty in $\Delta_{\mathrm{cd}}^{g} S_{m}\left(T_{m}, p_{m}\right)$, which was calculated by applying the propagation of uncertainty to the equation $\Delta_{\text {cd }}^{g} S_{m}\left(T_{m}, p_{m}\right)=\Delta_{\text {cd }}^{g} H_{m}\left(T_{m}, p_{m}\right) / T_{m}$.

${ }^{\mathrm{c}}$ Associated uncertainty was calculated by applying the propagation of uncertainty to equation $\Delta_{\mathrm{cd}}^{g} G_{m}^{0}=\Delta_{\mathrm{cd}}^{g} H_{m}^{0}-T \cdot \Delta_{\mathrm{cd}}^{g} S_{m}^{0}$. 
S4. Computational results.

Table S4. Computational results, at M05-2X and $\mathrm{Gn}(\mathrm{n}=3,4)$ levels of theory, for gallic (1) and ellagic (2) acids. Relative enthalpies $(\Delta H)$ of stable rotamers and their equilibrium molar fractions (populations).

\begin{tabular}{|c|c|c|c|c|c|c|}
\hline & & $\boldsymbol{E}_{\mathbf{0}}{ }^{\mathrm{a}}$ & $G_{298}{ }^{\text {a }}$ & $H_{298}{ }^{a}$ & $\Delta \boldsymbol{H}^{\mathrm{b}}$ & $\begin{array}{c}\text { Population } \\
(\%)\end{array}$ \\
\hline \multicolumn{7}{|c|}{ Gallic acid, 1} \\
\hline \multirow{4}{*}{$\begin{array}{l}\mathrm{M05-2X/} \\
6-311++G(d, p)\end{array}$} & $\mathbf{1}_{\mathrm{a}}$ & -646.493927 & -646.530781 & -646.481985 & 0.0 & 73.85 \\
\hline & $\mathbf{1}_{\mathrm{b}}$ & -646.492956 & -646.529797 & -646.481065 & 2.4 & 26.05 \\
\hline & $\mathbf{1}_{\mathrm{c}}$ & -646.487908 & -646.524201 & -646.476409 & 14.6 & 0.07 \\
\hline & $\mathbf{1}_{\mathrm{d}}$ & -646.487127 & -646.523588 & -646.475207 & 17.8 & 0.04 \\
\hline \multirow[t]{4}{*}{ G3 } & $\mathbf{1}$ & -646.125974 & -646.162622 & -646.113816 & 0.0 & 66.47 \\
\hline & $\mathbf{1}_{\mathrm{b}}$ & -646.125250 & -646.161966 & -646.113064 & 2.0 & 33.18 \\
\hline & $\mathbf{1}_{\mathrm{c}}$ & -646.120237 & -646.157001 & -646.107992 & 15.3 & 0.17 \\
\hline & $\mathbf{1}_{\mathrm{d}}$ & -646.120164 & -646.156979 & -646.107900 & 15.5 & 0.17 \\
\hline \multirow[t]{4}{*}{ G4 } & $\mathbf{1}_{\mathrm{a}}$ & -646.242809 & -646.279032 & -646.231014 & 0.0 & 64.20 \\
\hline & $\mathbf{1}_{\mathrm{b}}$ & -646.242198 & -646.278471 & -646.230378 & 1.7 & 35.44 \\
\hline & $\mathbf{1}_{\mathrm{c}}$ & -646.237249 & -646.273491 & -646.225434 & 14.6 & 0.18 \\
\hline & $\mathbf{1}_{\mathrm{d}}$ & -646.237178 & -646.273444 & -646.225347 & 14.9 & 0.17 \\
\hline \multicolumn{7}{|c|}{ Ellagic acid, 2} \\
\hline \multirow{6}{*}{$\begin{array}{l}\mathrm{M05}-2 \mathrm{X} / \\
6-311++G(d, p)\end{array}$} & $2 a_{a}$ & -1138.969444 & -1139.012643 & -1138.951732 & 0.0 & 99.1728 \\
\hline & $2_{b}$ & -1138.964102 & -1139.007529 & -1138.946122 & 14.7 & 0.4408 \\
\hline & $\mathbf{2}_{\mathrm{c}}$ & -1138.958053 & -1139.001408 & -1138.940140 & 30.4 & 0.0007 \\
\hline & $2_{\mathrm{d}}$ & -1138.958063 & -1139.000736 & -1138.940215 & 30.2 & 0.0003 \\
\hline & $2_{\mathrm{e}}$ & -1138.964026 & -1139.007402 & -1138.946076 & 14.8 & 0.3853 \\
\hline & $2_{\mathrm{f}}$ & -1138.957283 & -1138.999816 & -1138.939536 & 32.0 & 0.0001 \\
\hline
\end{tabular}

${ }^{\mathrm{a}}$ All values in units of Hartree/particle. ${ }^{\mathrm{b}}$ Values in in $\mathrm{kJ} \cdot \mathrm{mol}^{-1} \cdot E_{0}=$ Total Energies at $0 \mathrm{~K}$. $H_{298}=$ Enthalpies and $G_{298}=$ Gibbs Free Energies at 298.15 K. 
Figure S2. Molecular geometry of gallic acid (1) rotamers optimized at M05-2X/ 6$311++\mathrm{G}(\mathrm{d}, \mathrm{p})$ level of theory.

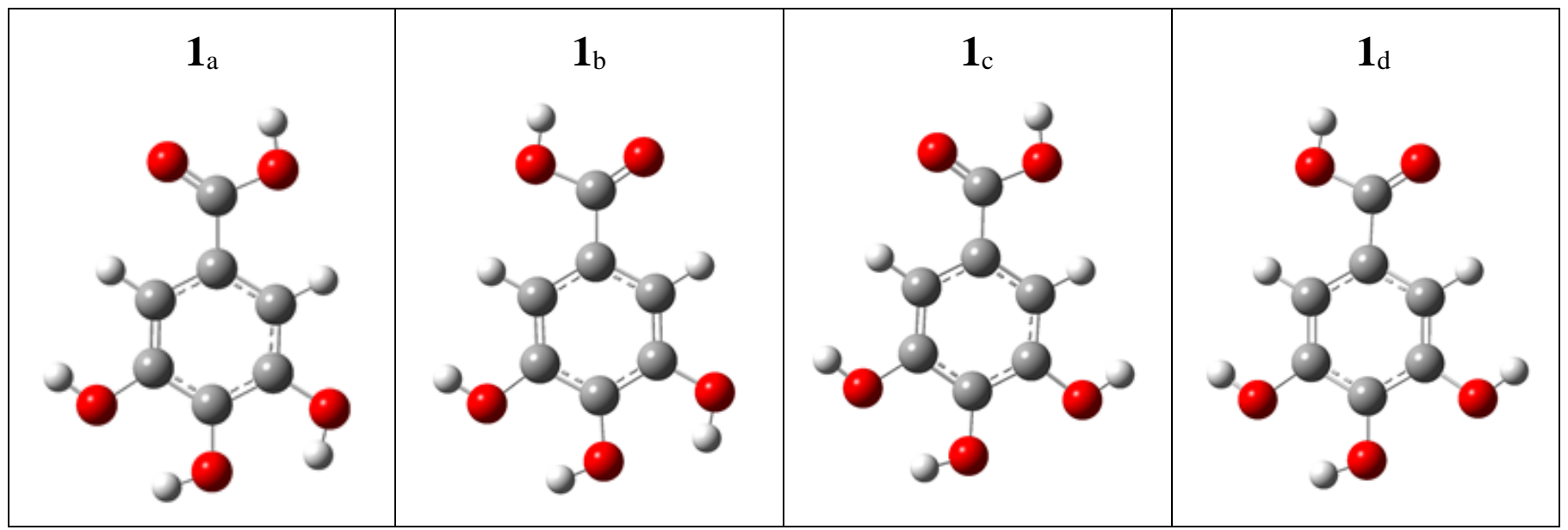

Figure S3. Molecular geometry of ellagic acid (2) rotamers optimized at M05-2X/ 6$311++\mathrm{G}(\mathrm{d}, \mathrm{p})$ level of theory.

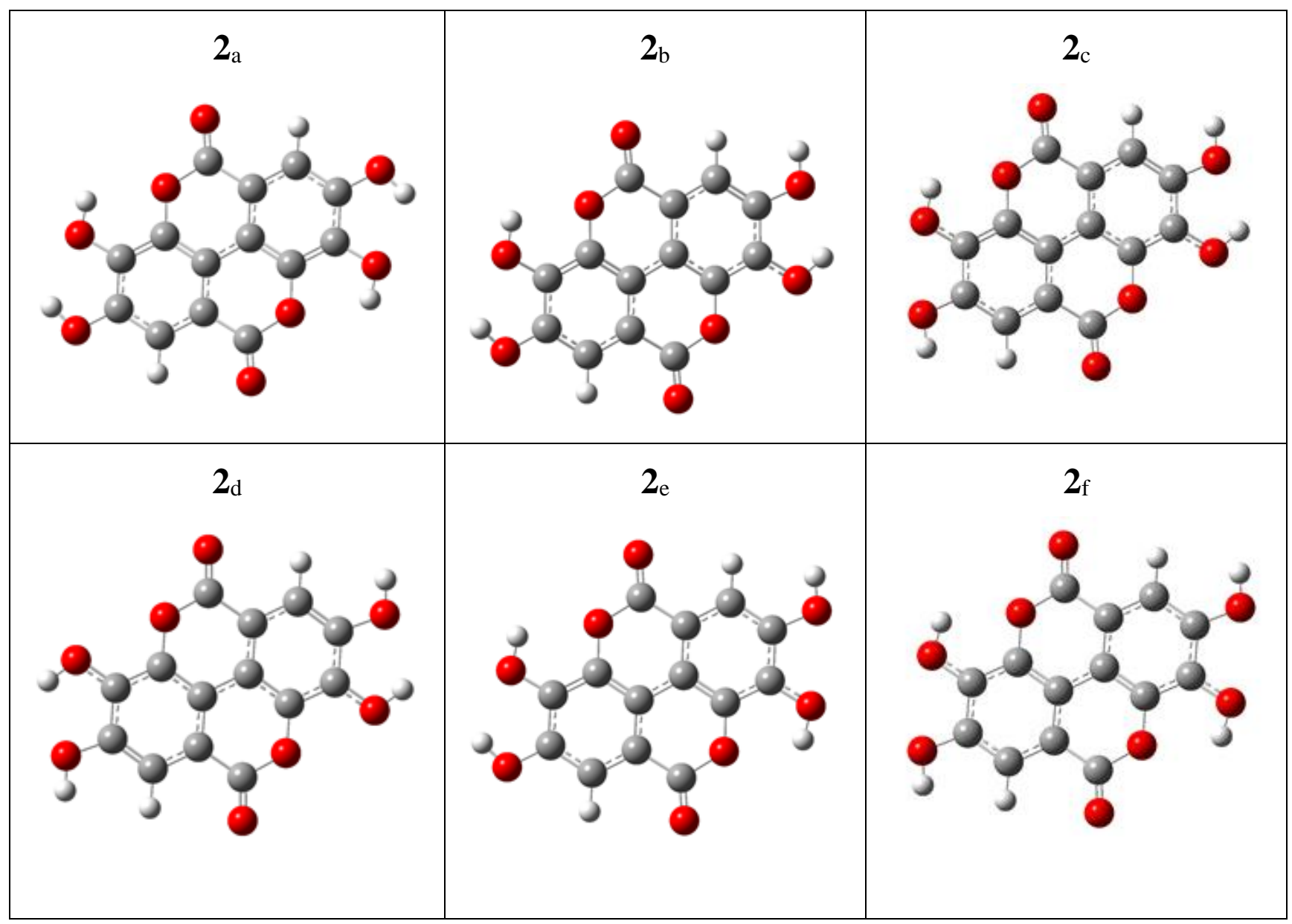




\section{S5. Thermochemical properties of pyrogallol.}

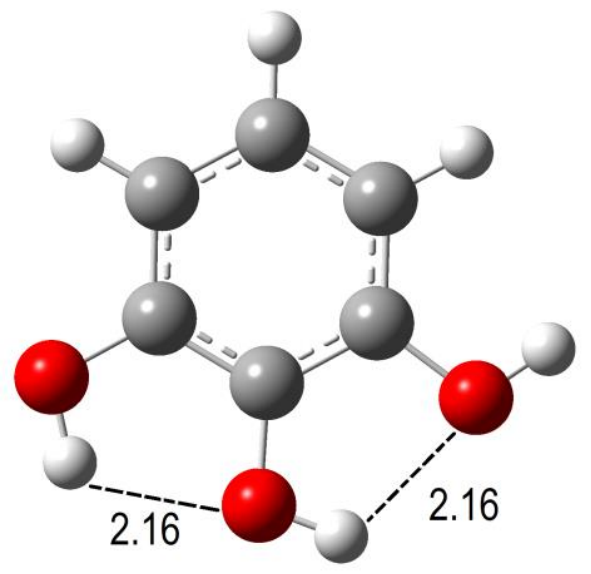

Figure S4. Molecular geometry of pyrogallol optimized at G3 level of theory

Table S5. Enthalpy of formation in the gas phase, $\Delta_{\mathrm{f}} H_{\mathrm{m}}^{0}(\mathrm{~g})$, of pyrogallol $(1,2,3-$ trihydroxybenzene) deduced from atomization and isodesmi-reactions methods. All values are given in $\mathrm{kJ} \cdot \mathrm{mol}^{-1}$.

\begin{tabular}{|c|c|c|c|}
\hline \multicolumn{2}{|c|}{$\Delta_{\mathrm{f}} H_{\mathrm{m}}^{0}(\mathrm{~g}) / \mathrm{kJ} \cdot \mathrm{mol}^{-1}$} \\
\hline \multirow{2}{*}{ Atomization } & \multicolumn{2}{|c|}{ Isodesmic reactions } \\
\cline { 4 - 5 } & Bond separation reaction (eq. S1) & \\
\hline $\mathrm{G} 3$ & $\mathrm{G} 4$ & & Equation S2 $^{\mathrm{b}}$ \\
\hline-452.3 & -447.8 & -453.5 & -457.6 \\
\hline
\end{tabular}

Evaluated at: ${ }^{a} \mathrm{M} 05-2 \mathrm{X} / 6-311++\mathrm{G}(3 \mathrm{df}, 2 \mathrm{p})$ and ${ }^{\mathrm{b}} \mathrm{M} 05-2 \mathrm{X} / 6-311++\mathrm{G}(\mathrm{d}, \mathrm{p})$ levels of theory.

Pyrogallol +9 methane $\longrightarrow 3 \cdot$ ethane $+3 \cdot$ ethene $+3 \cdot$ methanol

Pyrogallol + bencene $\longrightarrow$ benzoic acid + catechol 
S6. Thermochemical properties of chromeno[5,4,3-cde]chromene-5,10-dione (or specie

3).

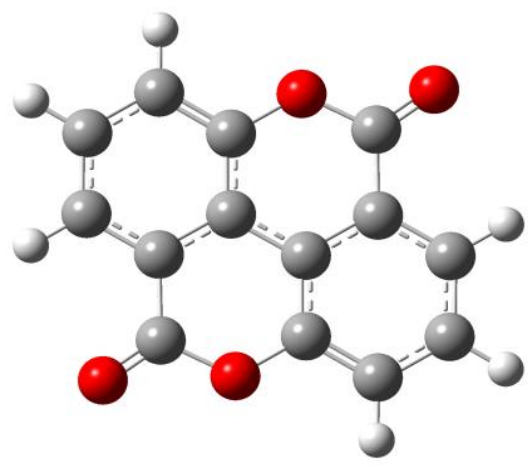

Figure S5. Molecular geometry of specie 3 optimized at M05-2X/6-311++G(d,p) level of theory

Table S6. Enthalpy of formation in the gas phase, $\Delta_{\mathrm{f}} H_{\mathrm{m}}^{0}(\mathrm{~g})$, of specie 3 . All values are given in $\mathrm{kJ} \cdot \mathrm{mol}^{-1}$.

\begin{tabular}{|c|c|c|}
\hline \multicolumn{2}{|c|}{$\Delta_{\mathrm{f}} H_{\mathrm{m}}^{0}(\mathrm{~g}) / \mathrm{kJ} \cdot \mathrm{mol}^{-1}$} \\
\hline \multirow{2}{*}{ Enthalpy } & \multicolumn{2}{|c|}{ Isodesmic reactions $^{\mathrm{b}}$} \\
\cline { 2 - 3 } changes $^{\mathrm{a}}$ & Bond separation reaction (eq. S3) $^{\mathrm{a}}$ & Equation S4 $^{\mathrm{b}}$ \\
\hline-410 & -413.4 & -412.5 \\
\hline
\end{tabular}

${ }^{\text {a }}$ Considering enthalpy changes associated to the removal of $\mathrm{OH}$ groups: $\approx 180 \mathrm{~kJ} \cdot \mathrm{mol}^{-1}$ for each $\mathrm{OH}$ removed.

${ }^{\mathrm{b}}$ Evaluated at M05-2X/6-311++G(d,p) level of theory.

$3+22$ methane $\longrightarrow 9 \cdot$ ethane $+6 \cdot$ ethene $+2 \cdot$ formaldehyde $+2 \cdot \operatorname{dimethyl}$ ether $(\mathrm{S} 3)$

$$
\mathbf{3}+4 \text { methanol } \longrightarrow \mathbf{2}+4 \text { methane }
$$


